\title{
Controllable Morphology of Sea-Urchin-like Nickel-Cobalt Carbonate Hydroxide as a Supercapacitor Electrode with Battery- like Behavior
}

\author{
Nutthapong Poompiew, Prasit Pattananuwat,* and Pranut Potiyaraj* \\ Cite This: ACS Omega 2021, 6, 25138-25150 \\ Read Online
}

ABSTRACT: Nickel-cobalt carbonate hydroxide with a three-dimensional (3D) sea-urchin-like structure was successfully developed by the hydrothermal process. The obtained structure enables the enhancement of charge/ion diffusion for the high-performance supercapacitor electrodes. The mole ratio of nickel to cobalt plays a vital role in the densely packed sea-urchin-like structure formation and electrochemical properties. At optimized nickel/cobalt mole ratio (1:2), the highest specific capacitance of $950.2 \mathrm{~F} \mathrm{~g}^{-1}$ at $1 \mathrm{~A} \mathrm{~g}^{-1}$ and the excellent cycling stability of $178.3 \%$ after 3000 charging/discharging cycles at $40 \mathrm{mV} \mathrm{s}^{-1}$ are achieved. This nickel-cobalt carbonate hydroxide electrode yields an energy density in the range of $42.9-15.8 \mathrm{Wh} \mathrm{kg}^{-1}$, with power density in the range of 285.0-2849.9 $\mathrm{W} \mathrm{kg}^{-1}$. The charge/discharge mechanism at the atomic level as monitored by time-resolved X-ray absorption spectroscopy (TR-XAS) indicates that the high capacitance behavior in a nickel-cobalt carbonate hydroxide is mainly dominated by cobalt carbonate hydroxide.

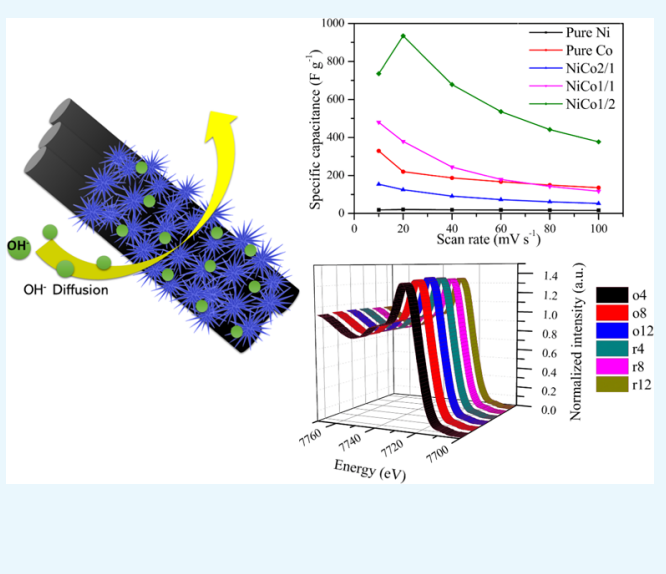

\section{INTRODUCTION}

Since electrical energy plays an important role in daily routines, requiring a fast charge feature, lightweight, high electrical storage capacity, and long-period usage. ${ }^{1,2}$ Unlike the battery such as Li-ion ${ }^{3,4}$ and hybrid type, ${ }^{5}$ supercapacitors (SCs) are the most attractive energy storage technology due to high power efficiency and long life cycles. ${ }^{6}$ Different redox-active materials such as polyaniline, ${ }^{7}$ polypyrrole, ${ }^{8}$ and metal oxide have been promoted as active materials for pseudocapacitors (PCs) due to high theoretical specific capacitance, high mechanical properties, and high stability. ${ }^{9}$ Transition-metal oxides with multiple oxidation states have been widely investigated for pseudocapacitor, such as bis(selanylidene)rhodium, ${ }^{10}$ manganese dioxide, ${ }^{11}$ molybdenum disulfide, ${ }^{12}$ manganese hexacyanoferrate, ${ }^{13}$ titanium dioxide, ${ }^{14}$ vanadium oxide, ${ }^{15}$ copper and nickel hexacyanoferrate, ${ }^{16}$ cobalt sulfide, ${ }^{17}$ cobalt selenide, ${ }^{18,19}$ cobalt ferrate, ${ }^{20}$ cobalt oxide, ${ }^{21}$ nickel hydroxide, $^{22}$ nickel cobaltite, ${ }^{23}$ etc. Many research efforts have been devoted to the nickel-cobalt complex due to high theoretical specific capacitance values, low cost, and long life cycles. ${ }^{24}$ Numerous attempts have been made to synthesize the nickel-cobalt complex such as direct oxidation and reduction, ${ }^{25}$ sol-gel method, ${ }^{24}$ electrodeposition, ${ }^{26}$ spraying process, $^{27}$ chemical vapor deposition, ${ }^{28}$ and hydrothermal process. $^{29}$ The hydrothermal process is an efficient way to create a new class material of metal oxide with the defined morphologies. Supercritical water formed under high pressure provides an excellent reaction environment for the crystal- lization of metal oxide particles. ${ }^{30}$ For example, the flower-like structure of nickel-cobalt oxide was synthesized by the hydrothermal technique with hexamethylenetetramine (HMTA), yielding the specific capacitance of $750 \mathrm{~F} \mathrm{~g}^{-1}$ at 1 $\mathrm{A} \mathrm{g}^{-1} \cdot{ }^{31}$ Nanosheet structure of the nickel-cobalt layered double hydroxide was obtained by two steps of hydro/ solvothermal process, demonstrating the high specific capacitance of $1497 \mathrm{~F} \mathrm{~g}^{-1}$ at $5 \mathrm{~mA} \mathrm{~cm}{ }^{-3}$. Porous nickelcobalt oxide nanowires via hydrothermal process yielded an excellent specific capacitance value of $1479 \mathrm{~F} \mathrm{~g}^{-1}$ at $1 \mathrm{~A} \mathrm{~g}^{-1} .32$

One important parameter for controlling the morphology and microstructure of the nickel/cobalt alloy complex is the modulating $\mathrm{Ni}$ /Co ratio. However, the nanostructured nickel/ cobalt alloy complex synthesis is hampered by the numerous complicated steps required and the difficulty in controlling phase morphology. As a result, the findings of the morphologycontrolled synthesis of the Ni-Co binary hydroxide for highperformance supercapacitors are still widely unknown. Furthermore, despite numerous studies of nickel and cobalt composites as SCs, the knowledge of the charge-discharge storage mechanisms remains hazy. To understand the behavior

Received: April 22, 2021

Accepted: September 13, 2021

Published: September 24, 2021 


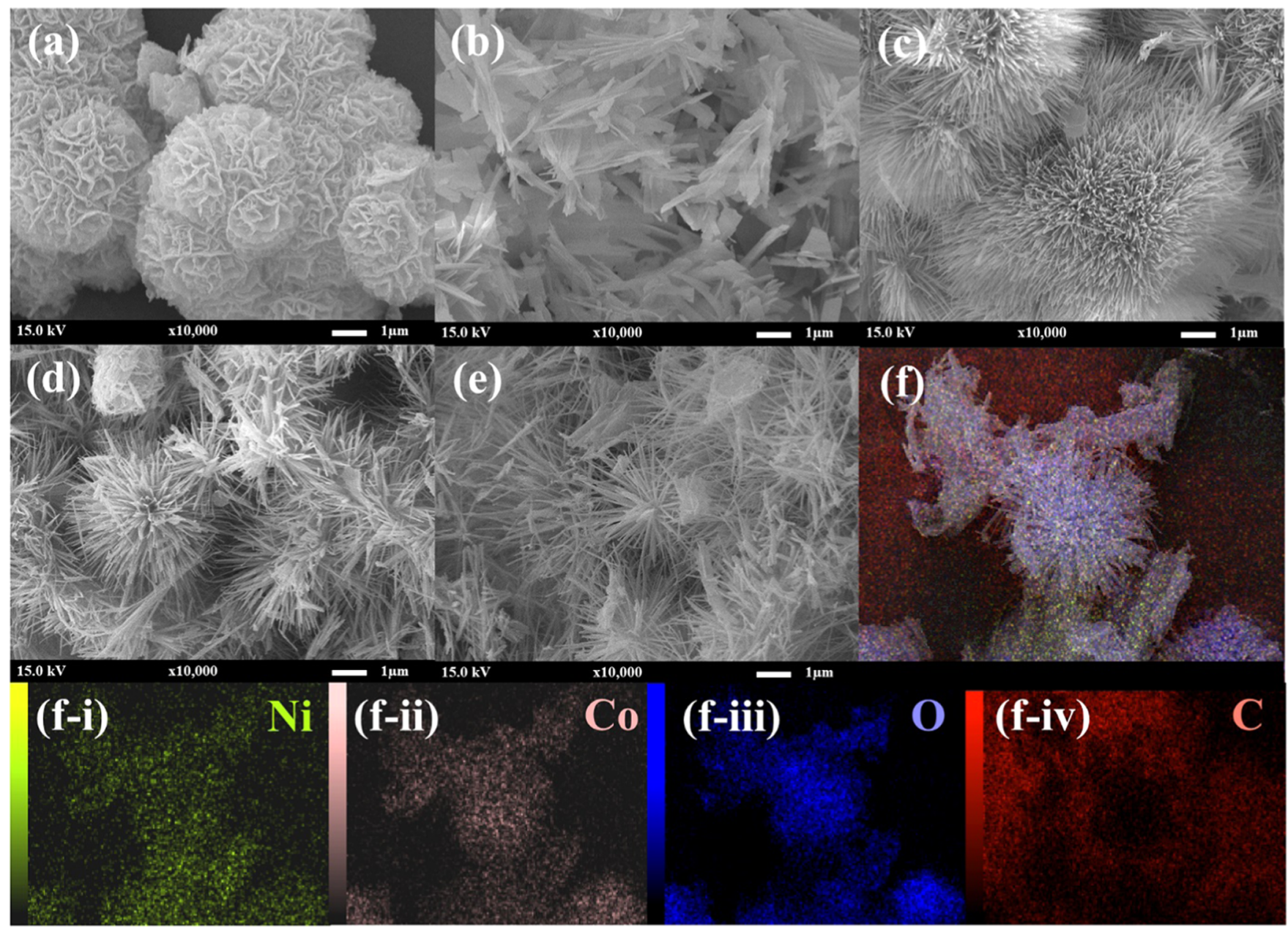

Figure 1. Representative SEM micrographs of (a) pure Ni, (b) pure Co, (c) NiCo2/1, (d) NiCo1/1, and (e) NiCo1/2 scale at $1 \mu \mathrm{m}$ and (f) elemental mapping of $\mathrm{NiCo} 1 / 2$ sample for (f-i) nickel, (f-ii) cobalt, (f-iii) oxygen, and (f-iv) carbon element.

at the atomic level, a charge/discharge mechanism analysis using time-resolved X-ray absorption spectroscopy (TR-XAS) is also proposed.

\section{RESULT AND DISCUSSION}

2.1. Morphology Study. Scanning electron microscopy (SEM) images of the as-prepared nickel-cobalt at different ratios of $\mathrm{Ni}$ to Co salt solution, as shown in Figure 1, show remarkable differences in surface morphology in each sample, indicating that the morphology of the as-prepared $\mathrm{Ni}-\mathrm{Co}$ complex is sensitive to the mole ratio of $\mathrm{Ni}$ to $\mathrm{Co}$ for the hydrothermal process. As seen in Figure 1a, the as-prepared nickel carbonate hydroxide demonstrates the growth of threedimensional (3D) flower-like microstructures assembled from nanoflake structures. Meanwhile, cobalt carbonate hydroxide exhibits a nanoflake-like structure in a rectangular shape as shown in Figure $1 \mathrm{~b}$. At a high ratio of $\mathrm{Ni}$ to $\mathrm{Co}(2$ to 1$)$, the $\mathrm{Ni}-\mathrm{Co}$ complex shows a sea-urchin-like structure, originating from the densely packed nanoneedle in a 3D core structure (Figure 1c). The less-dense nanoneedle packing in 3D seaurchin-like structure is observed at the $\mathrm{Ni} / \mathrm{Co}$ ratio of $1: 1$ and 1:2 as seen in Figure 1d,e, respectively. The imperfect urchinlike shape of the $\mathrm{Ni}-\mathrm{Co}$ complex occurs with the nanonoodlelike structure at a high ratio of Co to $\mathrm{Ni}$ (2 to 1$)$, implying that the growth of needle shape in the core structure of sea urchin is disturbed with increasing cobalt content in the $\mathrm{Ni} / \mathrm{Co}$ ratio.
The element composition analysis of samples at different $\mathrm{Ni}$ / Co ratios is further investigated. Figure if presents the element mapping of the $\mathrm{Ni} / \mathrm{Col} / 2$ sample, confirming the presence of $\mathrm{Ni}, \mathrm{Co}, \mathrm{O}$, and $\mathrm{C}$ elemental distribution on the surface of the $\mathrm{NiCo} 1 / 2$ sample (Figure 1f-i-f-iv). Furthermore, the energydispersive X-ray spectrometry (EDS) for the $\mathrm{Ni}-\mathrm{Co}$ complex oxide samples at different $\mathrm{Ni}$-to-Co ratios were analyzed as shown in Table 1 . The designed feeding for the Ni/Co mole

Table 1. Percentage of Elemental Atom from EDS Results

\begin{tabular}{crr} 
sample & \multicolumn{1}{c}{$\mathrm{Ni}(\%)$} & \multicolumn{1}{c}{ Co $(\%)$} \\
$\mathrm{NiCo} 2 / 1$ & $13.12 \pm 0.14$ & $14.6 \pm 0.13$ \\
$\mathrm{NiCo} 1 / 1$ & $13.40 \pm 0.16$ & $20.18 \pm 0.17$ \\
$\mathrm{NiCo} 1 / 2$ & $5.01 \pm 0.08$ & $17.72 \pm 0.13$
\end{tabular}

ratios of $2: 1,1: 1$, and $1: 2$ samples reveal the actual $\mathrm{Ni} / \mathrm{Co}$ ratios of $1: 1,1: 1.5$, and $1: 3.5$, respectively. This result indicates that the high reactivity of cobalt ion is superior to nickel ion in our experiment.

The surface area characteristic of all samples is investigated using the $\mathrm{N}_{2}$ adsorption/desorption isotherms as shown in Figure 2. All samples can be categorized as an isotherm of type II with a hysteresis loop of type $\mathrm{H} 3$, indicating a typical macroporous structure of different sizes. ${ }^{33,34}$ The as-prepared $\mathrm{NiCo} 1 / 2$ exhibits the highest $\mathrm{N}_{2}$ gas absorption, implying the 


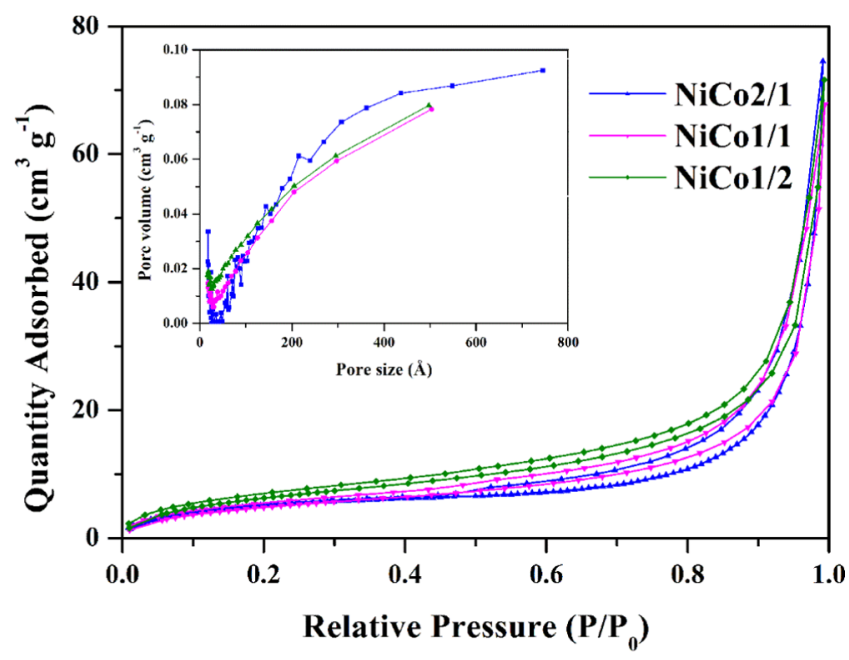

Figure 2. $\mathrm{N}_{2}$ adsorption/desorption isotherm and pore size distribution of the different ratios of nickel-cobalt carbonate hydroxide.

highest surface area of the nanoneedle sea-urchin-like structure. The specific surface area and porosity parameter are calculated as shown in Table S2. Obviously, the specific surface area of $\mathrm{NiCol} / 2$ exhibits the highest area of $24.84 \mathrm{~m}^{2}$ $\mathrm{g}^{-1}$ with the smallest average pore size of $155.3 \AA$. The Brunauer-Emmett-Teller (BET) results are in agreement with the SEM results, demonstrating that the decrease in needle density of 3D sea-urchin-like structure can facilitate an ion/charge diffusion pathways for electrochemical active surface area (ECSA).

2.2. Characterization. $\mathrm{X}$-ray diffraction (XRD) technique was performed to investigate the crystal structure of the $\mathrm{Ni}-$ Co samples at different Ni/Co ratios, as shown in Figure 3.

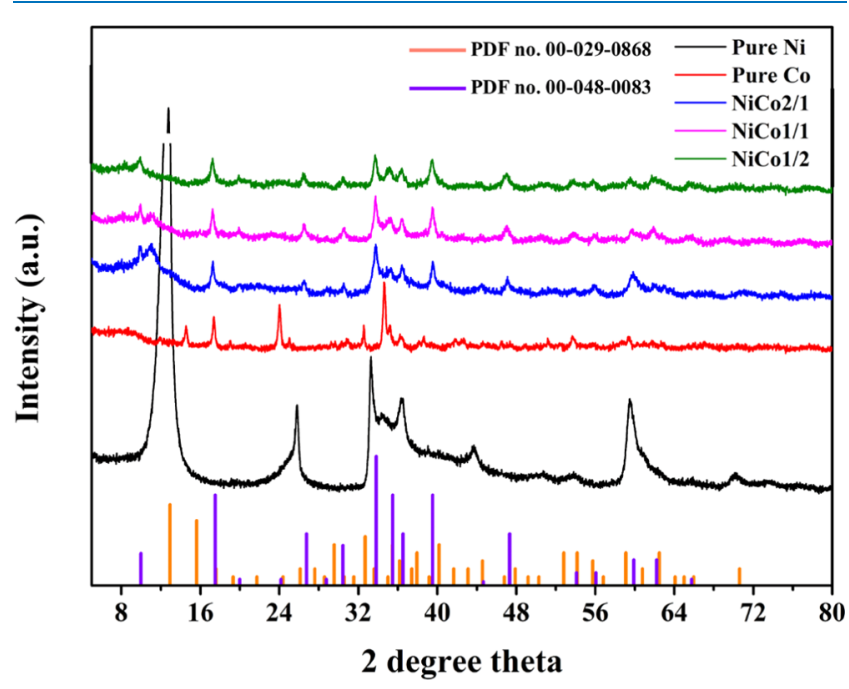

Figure 3. XRD pattern of pure $\mathrm{Ni}$, pure $\mathrm{Co}, \mathrm{NiCo} / 1, \mathrm{NiCo} / 1 / 1$, $\mathrm{NiCo} 1 / 2$, and PDF standard pattern.

The as-prepared pristine $\mathrm{Ni}$ exhibits the strong diffraction peak at $12.8,25.8,33.2,36.4$, and $59.5^{\circ}$, according to the (040), (260), (221), (071), and (0131) crystal planes of nickel carbonate hydroxide (PDF no. 00-029-0868), respectively. ${ }^{35}$ The as-prepared pristine Co reveals the diffraction peaks at 9.8, 17.3, 24.0, and $34.6^{\circ}$ corresponding to PDF no. 00-048-0083, ascribed to cobalt carbonate hydroxide. ${ }^{36}$ For all diffraction patterns of the as-prepared $\mathrm{Ni}-\mathrm{Co}$ samples, the XRD patterns reveal the diffraction peak of both nickel carbonate hydroxide and cobalt carbonate hydroxide. Compared with pristine $\mathrm{Ni}$ and $\mathrm{Co}$, nickel carbonate hydroxide and cobalt carbonate hydroxide exhibit a gradual shift in the XRD pattern, resulting from the crystal intercalation of cobalt carbonate hydroxide and nickel carbonate hydroxide. Furthermore, the intensity of each characteristic peak relatively depends on the amount of initial $\mathrm{Ni}^{2+}$ and $\mathrm{Co}^{2+}$. In other words, as the $\mathrm{Ni} / \mathrm{Co}$ ratio decreases, the peak of nickel carbonate hydroxide becomes smaller and narrower.

The further chemical compositions analysis of the $\mathrm{Ni} / \mathrm{Co}$ ratio at 1:2 is investigated by X-ray photoelectron spectroscopy (XPS) technique. Figure 4a reveals the survey XPS spectra of nickel-cobalt carbonate hydroxide sample at ratio of $\mathrm{Ni} / \mathrm{Co}$ of $1: 2$, confirming the presence of $\mathrm{Ni}, \mathrm{Co}, \mathrm{O}$, and $\mathrm{C}$ atoms. Two spin-orbitals of $\mathrm{Ni} 2 \mathrm{p}$ at $\mathrm{Ni} 2 \mathrm{p}_{3 / 2}$ and $\mathrm{Ni} 2 \mathrm{p}_{1 / 2}$ with two satellite peaks (denoted as "Sat.") are identified with binding energy at 856.6 and $874.2 \mathrm{eV}$, respectively, described as $\mathrm{Ni}^{2+}$ (seen in Figure $4 \mathrm{~b}) .{ }^{35}$ Two spin-orbitals peaks of Co $2 \mathrm{p}_{3 / 2}$ and Co $2 \mathrm{p}_{1 / 2}$ are illustrated in Figure $4 \mathrm{c}$. The peaks at 798.5 and $782.9 \mathrm{eV}$ correspond with Co $2 \mathrm{p}_{3 / 2}$ and $2 \mathrm{p}_{1 / 2}$ of $\mathrm{Co}^{2+}$. In addition, the peaks at 792.7 and $776.1 \mathrm{eV}$ are attributed to Co $2 \mathrm{p}_{3 / 2}$ and $2 \mathrm{p}_{1 / 2}$ of $\mathrm{Co}^{3+} \cdot{ }^{37}$ Two species of oxygen are observed in Figure $4 \mathrm{~d}$. The higher intensity peak at $533.0 \mathrm{eV}$ can be ascribed as a typical metal carbonate species while the peak at $532.1 \mathrm{eV}$ is designated to hydroxyl groups. ${ }^{38}$ The deconvoluted C 1s spectra (Figure 4e) are also observed at 283.6 and 285.3 $\mathrm{eV}$, corresponding with the characteristic binding energy of $\mathrm{Ni}$ carbonate and Co carbonate species, respectively. The extra peak at 287.6 and 289.0 is ascribed to the carbon hydroxyl and C carbonate species, respectively. ${ }^{34,35,37}$ Thus, these results suggest the main valence state of nickel-cobalt complex is $\mathrm{Ni}^{2+}, \mathrm{Co}^{2+}$, and $\mathrm{Co}^{3+}$, which is in good agreement with the previous report of the mixed nickel-cobalt carbonate hydroxide.

In addition, the comparative XPS spectra of the mixed nickel-cobalt carbonate hydroxide samples at different Ni-to$\mathrm{Co}$ ratios were observed. The peak positions of $\mathrm{Ni} 2 \mathrm{p}$ for all mixed $\mathrm{Ni}-\mathrm{Co}$ carbonate hydroxide samples reveal the almost same (Figure 5a-c), implying the similar chemical compositions of $\mathrm{Ni}^{2+}$. However, for Co $2 \mathrm{p}$ pattern, the presence of the peak intensities at $776.1 \mathrm{eV}$ for Co $2 \mathrm{p}_{3 / 2}$ and $792.7 \mathrm{eV}$ for Co $2 \mathrm{p}_{1 / 2}$ is manifestly increased with decreasing $\mathrm{Ni} / \mathrm{Co}$ ratio (Figure 5e,f). This result suggests the high activity of the formation of $\mathrm{Co}$ (III) carbonate at a high cobalt concentration. The difference in peak intensities are also recognized, corresponding to the $\mathrm{Ni} / \mathrm{Co}$ ratio in each sample. It can be seen that the peak intensity ratio of $\mathrm{Ni} 2 \mathrm{p} / \mathrm{Co} 2 \mathrm{p}$ tends to decrease with increasing cobalt content (Table S1).

2.3. Electrochemical Properties Results. The comparative $\mathrm{CV}$ study has been used to evaluate the influence of the $\mathrm{Ni} / \mathrm{Co}$ ion ratio on the electrochemical characteristics of the sample electrodes. As seen in Figure 6a, all sample electrodes exhibit the pair redox peak of a reversible Faradic redox reaction, confirming that the charge storage mechanism of nickel-cobalt carbonate hydroxide is mainly conducted by pseudocapacitance behaviors. Obviously, the diverse redox characteristic and electrochemical performance of all of the asprepared electrodes reveal different Faradic characteristics, resulting from the distinct proportional ratio of $\mathrm{Ni}$ to $\mathrm{CO}$ in nickel-cobalt carbonate hydroxide. ${ }^{39}$ For pristine nickel oxide electrodes, the two obvious peaks of oxidation and reduction 

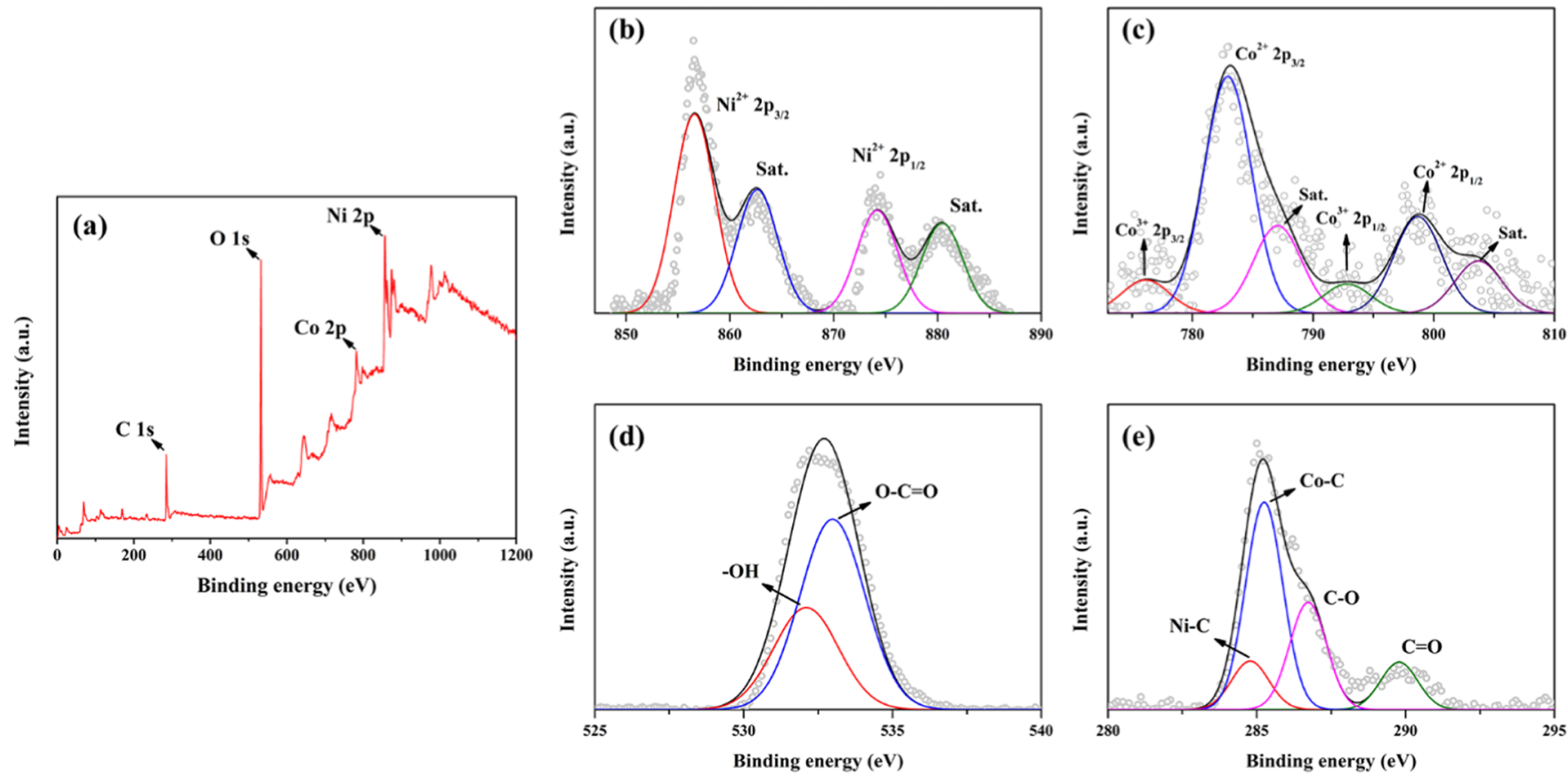

Figure 4. XPS spectrum of (a) elemental survey, (b) Ni 2p, (c) Co 2p, (d) O 1s, and (e) C 1s of NiCo1/2 sample.
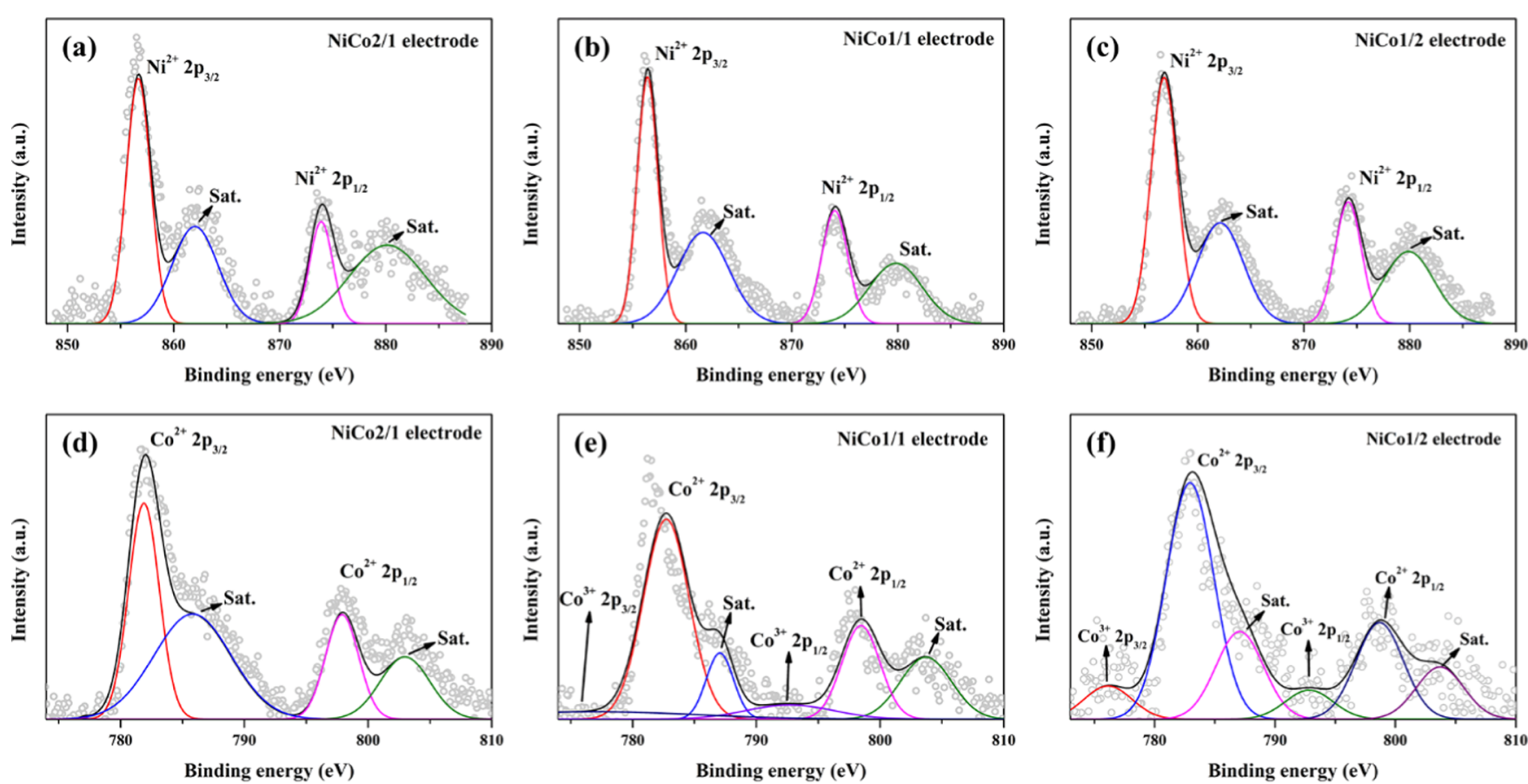

Figure 5. XPS spectra of (a) NiCo2/1, (b) NiCo1/1, and (c) NiCo1/2 for $\mathrm{N} 2 \mathrm{p}$ and (d) NiCo2/1, (e) NiCo1/1, and (f) NiCo1/2 for C 2p.

reaction peaks are observed at the corresponding peak potentials of 0.28 and $0.18 \mathrm{~V}$, respectively. This result may occur from the formation of the $\mathrm{Ni}_{2}(\mathrm{OH})_{2} \mathrm{CO}_{3} \rightleftharpoons \mathrm{NiOOH}$ during the $\mathrm{CV}$ cycling in $\mathrm{KOH}$ aqueous solution. ${ }^{40}$ The pure cobalt carbonate hydroxide electrode reveals one anodic peak at $0.05 \mathrm{~V}$ and two cathodic peaks at -0.15 and $0.35 \mathrm{~V}$, causing by the phase transformation of $\mathrm{Co}\left(\mathrm{CO}_{3}\right)_{0.5}(\mathrm{OH}) \rightleftharpoons \mathrm{CoOOH}$ $\rightleftharpoons \mathrm{CoO}_{2}{ }^{41} \mathrm{CV}$ curves of mixed nickel-cobalt carbonate hydroxide electrodes exhibit a similar shape but shift in their redox position, indicating that the capacitive response related to the ratio of $\mathrm{M}-\mathrm{O}, \mathrm{M}-\mathrm{O}-\mathrm{OH}$, and $\mathrm{M}$ carbonate hydroxide ( $\mathrm{M}$ represents $\mathrm{Ni}$ or $\mathrm{Co}$ ) in composite electrodes. The plausible redox mechanisms of nickel and cobalt carbonate hydroxide are illustrated in eqs $1-3$. $^{42}$

$$
\begin{aligned}
& \mathrm{Ni}_{2}(\mathrm{OH})_{2} \mathrm{CO}_{3}+4 \mathrm{OH}^{-} \\
& \leftrightarrow \mathrm{NiOOH}+\mathrm{NiCO}_{3}+2 \mathrm{H}_{2} \mathrm{O}+2 \mathrm{e}^{-} \\
& 2 \mathrm{Co}\left(\mathrm{CO}_{3}\right)_{0.5}(\mathrm{OH})+\mathrm{OH}^{-} \\
& \leftrightarrow \mathrm{CoOOH}+\mathrm{CoCO}_{3}+\mathrm{H}_{2} \mathrm{O}+\mathrm{e}^{-} \\
& \mathrm{CoOOH}+\mathrm{OH}^{-} \leftrightarrow \mathrm{CoO}_{2}+\mathrm{H}_{2} \mathrm{O}+\mathrm{e}^{-}
\end{aligned}
$$



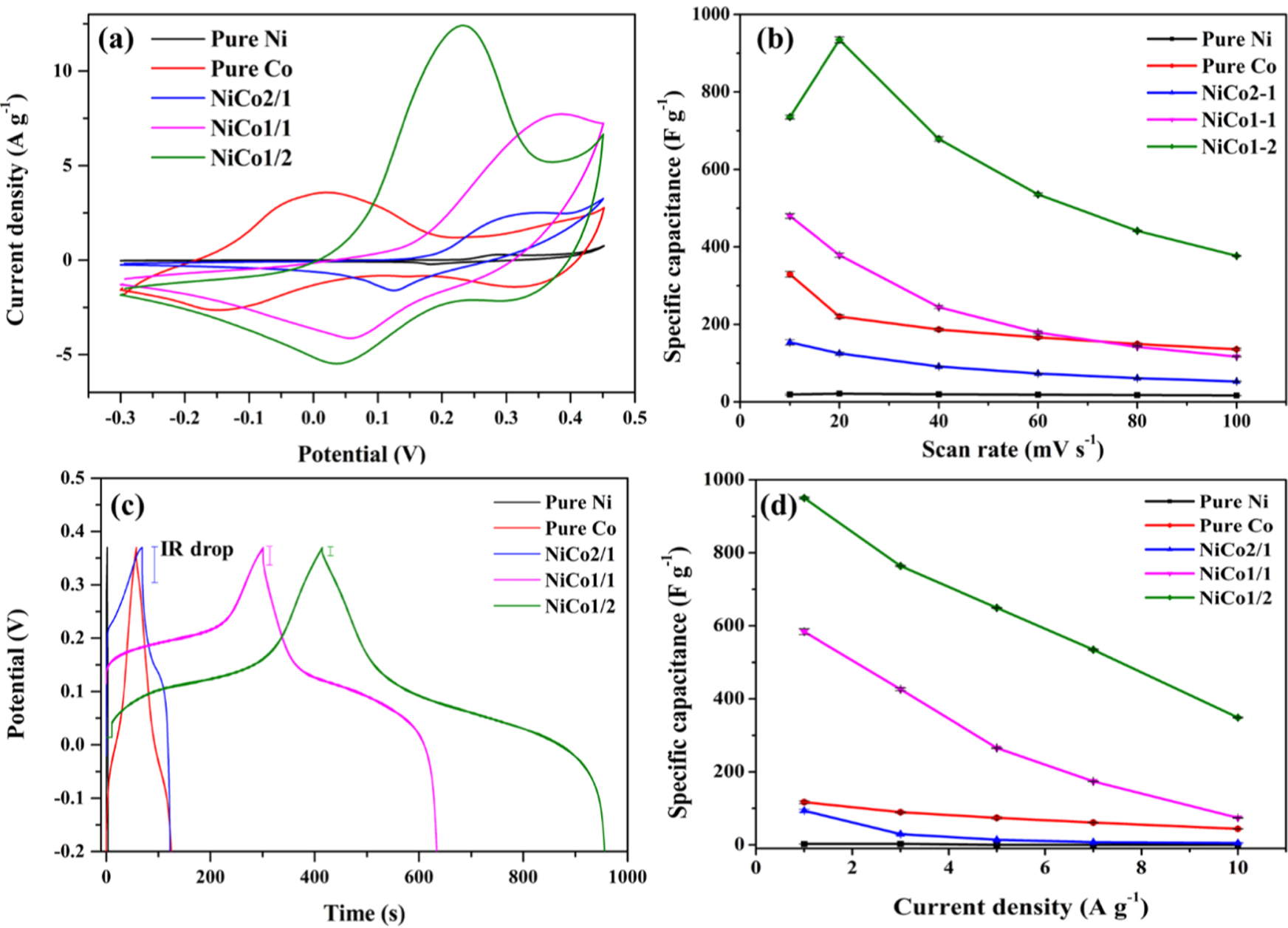

Figure 6. (a) CV curves of different nickel/cobalt ratios at a scan rate of $10 \mathrm{mV} \mathrm{s}^{-1}$, (b) specific capacitance as a function of scan rate from 10 to $100 \mathrm{mV} \mathrm{s}^{-1}$, (c) galvanostatic charge-discharge (GCD) result of different nickel/cobalt ratios at the current density of $1 \mathrm{~A} \mathrm{~g}^{-1}$, and (d) specific capacitance as a function of current density from 1 to $10 \mathrm{~A} \mathrm{~g}^{-1}$.

Principally, the cyclic CV curve area is proportional to the electrochemically active surface area, indicating a sufficient number of electroactive sites at heterointerfaces during redox reactions. ${ }^{43}$ The precursor ratio of $\mathrm{Ni}$ to $\mathrm{Co}$ salt for the hydrothermal process is the key factor influencing the electrocapacitance properties of the sample electrodes. Manifestly, the nickel-cobalt carbonate hydroxide electrode at the Ni-to- $\mathrm{CO}$ ratio of $1: 2$ demonstrates the highest $\mathrm{CV}$ area, implying the highest electrochemical active surface area relative to the other electrode samples. In contrast, the pure nickel carbonate hydroxide electrode reveals the lowest $\mathrm{CV}$ area, implying the lowest capacitance performance. The enhanced performance of $\mathrm{NiCo} 1 / 2$ due to the presence of the mixed nickel-cobalt carbonate hydroxide may be associated with the increase in conductivity related to electrochemical properties. The highest current density of the $\mathrm{CV}$ curve for $\mathrm{NiCo} 1 / 2$ is ascribed to the conversion of $\mathrm{M}(\mathrm{OH})_{2} \mathrm{CO}_{3}$ to $\mathrm{M}-\mathrm{O}-\mathrm{OH}$ and $\mathrm{M}-\mathrm{CO}_{3}$, which has gained more electron-transfer reaction as mentioned in eqs $1-3$. The calculated specific capacitance by $\mathrm{CV}$ of nickel-cobalt carbonate hydroxide at different Ni-toCO ratios of 1:0, 2:1, 1:1, 1:2, and 0:1 are 19.3, 153.7, 480.0, 735.33 , and $329.33 \mathrm{~F} \mathrm{~g}^{-1}$ at $10 \mathrm{mV} \mathrm{s}^{-1}$, respectively. Figure $6 \mathrm{~b}$ shows the specific capacitance calculated by the CV curve of nickel-cobalt at different ratios as a function of the scan rate from 10 to $100 \mathrm{mV} \mathrm{s}^{-1}$. It is clear that the nickel-cobalt carbonate hydroxide electrode at a ratio of 1:2 also exhibits high rate performance, maintaining the high specific capacitance of more than $400 \mathrm{~F} \mathrm{~g}^{-1}$ even at a high scan rate of $100 \mathrm{mV} \mathrm{s}^{-1}$.

The GCD results of all sample electrodes at a current density of $1 \mathrm{~A} \mathrm{~g} \mathrm{~g}^{-1}$ with the potential window ranging from -0.2 to $0.37 \mathrm{~V}$ are presented in Figure $6 \mathrm{c}$. The GCD evidence of all samples displays a plateau curve with low internal resistance (IR drop), indicating a good capacitance behavior. ${ }^{44}$ Among them, the nickel-cobalt carbonate hydroxide electrode at the ratio of 1:2 demonstrates the longest plateau discharging time, indicating the highest specific capacitance. An increase in the cobalt-to-nickel ratio leads to a decrease in the internal resistance in electrode samples, indicating that electrical capacitance improves as the cobalt component increases. The calculated specific capacitance from the GCD results of electrode samples at different Ni-to-CO ratios of 1:0, 2:1, $1: 1,1: 2$, and $0: 1$ are $2.4,93.5,584.1,950.2$, and $117.0 \mathrm{~F} \mathrm{~g}^{-1}$ at a current density $1 \mathrm{~A} \mathrm{~g}^{-1}$, respectively. Further investigation of the rate performance of electrode samples at different current densities ranging from 1 to $10 \mathrm{~A} \mathrm{~g} \mathrm{~g}^{-1}$ is shown in Figure $6 \mathrm{~d}$. These results show a good agreement with $\mathrm{CV}$ results, demonstrating the high performance of nickel-cobalt carbonate hydroxide electrode at the $\mathrm{Ni} / \mathrm{Co}$ ratio of $1: 2$ is superior to that of other electrodes even at high current density $\left(>400 \mathrm{~F} \mathrm{~g}^{-1}\right.$ at $10 \mathrm{~A} \mathrm{~g}^{-1}$ ). On the basis of these evidences along with the SEM and BET results, the obtained heterostructure of 

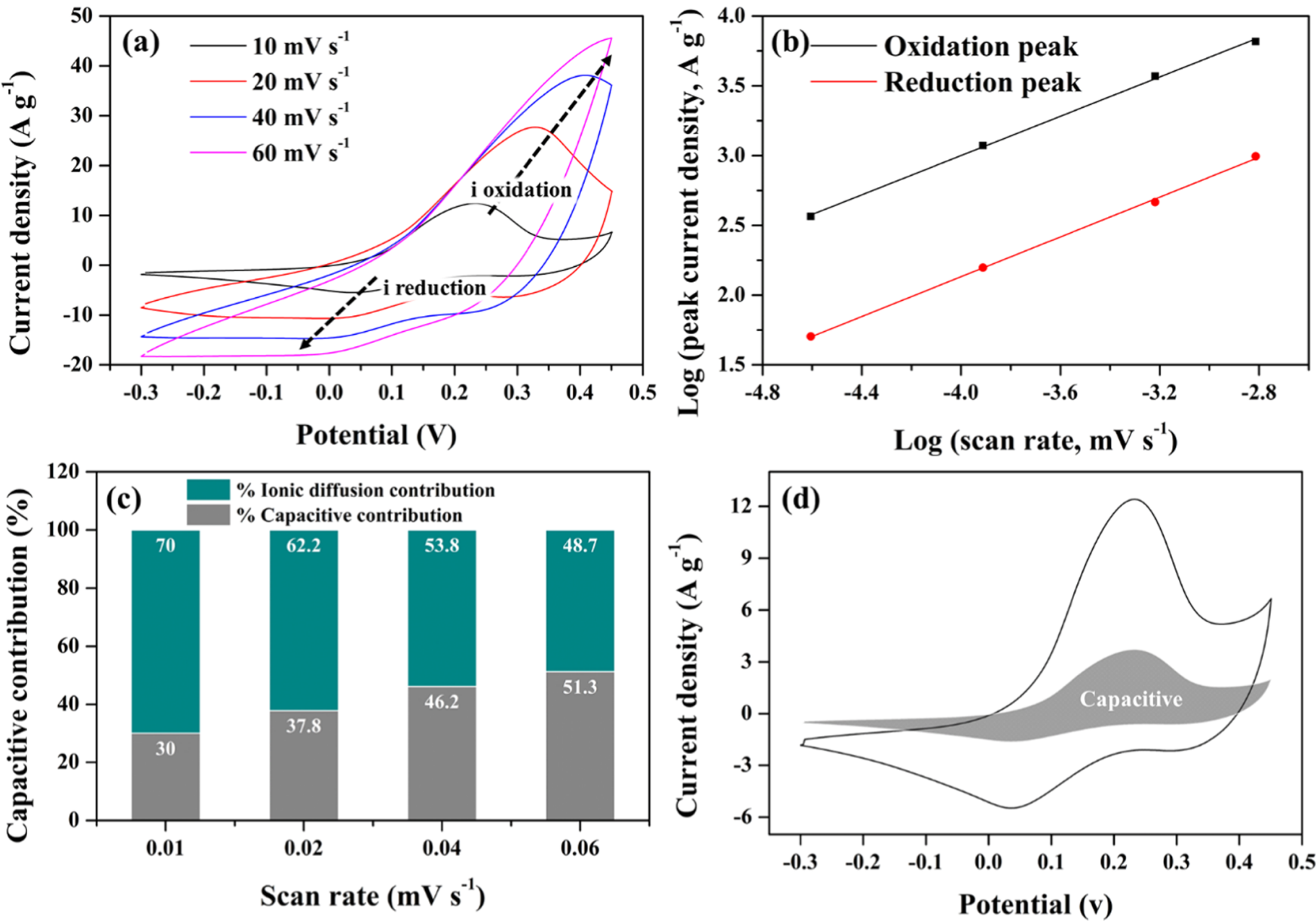

Figure 7. (a) CV curves of NiCo1/2 electrode at different scan rates from 10 to $60 \mathrm{mV} \mathrm{s}^{-1}$, (b) the corresponding plots between log (current peak) and $\log$ (scan rate) at oxidation and reduction peaks, (c) capacitive and ionic diffusion contributions of NiCo1/2 at different scan rates, and (d) comparative $\mathrm{CV}$ curve of the capacitive contribution in the $\mathrm{NiCo1} / 2$ electrode at $10 \mathrm{mV} \mathrm{s}^{-1}$ scan rate.

urchin-like structure with the nanonoodle-like structure of samples at $\mathrm{Ni} / \mathrm{Co}$ ratio of $1: 2$ is the optimized combination morphology for the coexistence of nickel and cobalt carbonate hydroxide (Figure 1e) with the highest BET surface area, yielding the highest capacitance. Meanwhile, the large urchinlike structure of electrode samples at the $\mathrm{Ni} / \mathrm{Co}$ ratios of 2:1 (Figure 1c) and 1:1 (Figure 1d) reveals the presence of highly dense packing and agglomerate structure, which decrease the ion diffusion and charge transfer, resulting in a low redox surface activity in the inner active site. Thus, the great improvement of redox capacitance behavior of electrode samples at the $\mathrm{Ni} / \mathrm{Co}$ ratio of 1:2 can be explained as follows: (i) highly electroactive site-enriched cobalt carbonate hydroxide incorporated with nickel carbonate hydroxide for faradic reaction and (ii) the perfect densely packed sea-urchin-like structure provides the shortcut pathway for ion diffusion.

To further emphasize the electrochemical storage mechanism of nickel-cobalt carbonate hydroxide electrode at the $\mathrm{Ni} / \mathrm{Co}$ ratio of $1: 2, \mathrm{CV}$ techniques of the electrode sample are complemented at different scan rates from 10 to $60 \mathrm{mV} \mathrm{s}^{-1}$, as shown in Figure 7a. It is seen that the pair redox peaks of the $\mathrm{CV}$ curve reveal a slight shift in the higher potential with the increasing scan rate. The logarithmic relationship between the peak currents $(i)$ and scan rate $(\nu)$ is calculated using the power law to exemplify the charge storage mechanism as in eqs 4 and 5

$$
\begin{aligned}
& i=a \nu^{b} \\
& \log (i)=b \log (\nu)+\log (a)
\end{aligned}
$$

where the $b$ value prefers the slope of $\log (i)$ and $\log (\nu)$ plots. The charge/discharge process is controlled by ionic diffusion when the $\mathrm{b}$ value is close to 0.5 , While the $b$ value reaches 1 , the electrochemical performance of the electrode is dominated by pseudocapacitive behavior. From the fitting curves of the $\mathrm{NiCo} 1 / 2$ electrode in Figure $7 \mathrm{~b}$, the calculated $\mathrm{b}$ of the oxidation and reduction peaks are 0.7 and 0.71 , respectively, indicating that the charge/discharge mechanism of the $\mathrm{NiCol} /$ 2 electrode is majorly controlled by ion diffusion participating in the pseudocapacitive behavior. ${ }^{45}$ The rate performance contribution mechanism of this electrode is calculated to compare the capacitive contribution with the relation of eq 6

$$
i=k_{1} v+k_{2} v^{1 / 2}
$$

With the plotting of $i / \nu^{1 / 2}$ vs $\nu^{1 / 2}, k_{1}$ and $k_{2}$ are calculated from the slope and the $y$-axis interception, respectively. As eq 6 , the term of the diffusion-controlled behavior is referred to as $k_{2} \nu^{1 / 2}$ and that of the capacitive contribution behavior as $k_{1} \mathrm{v}$. Figure $7 \mathrm{c}$ presents the mechanism contribution of $\mathrm{NiCol} / 2$ electrodes at different scan rates. It is clear that as the scan rate increases, the pseudocapacitive contribution is increased. The pseudocapacitive contribution of $\mathrm{NiCol} / 2$ is $30.0,37.8,46.2$, and $51.3 \%$ at $10,20,40$, and $60 \mathrm{mV} \mathrm{s}^{-1}$, respectively, 

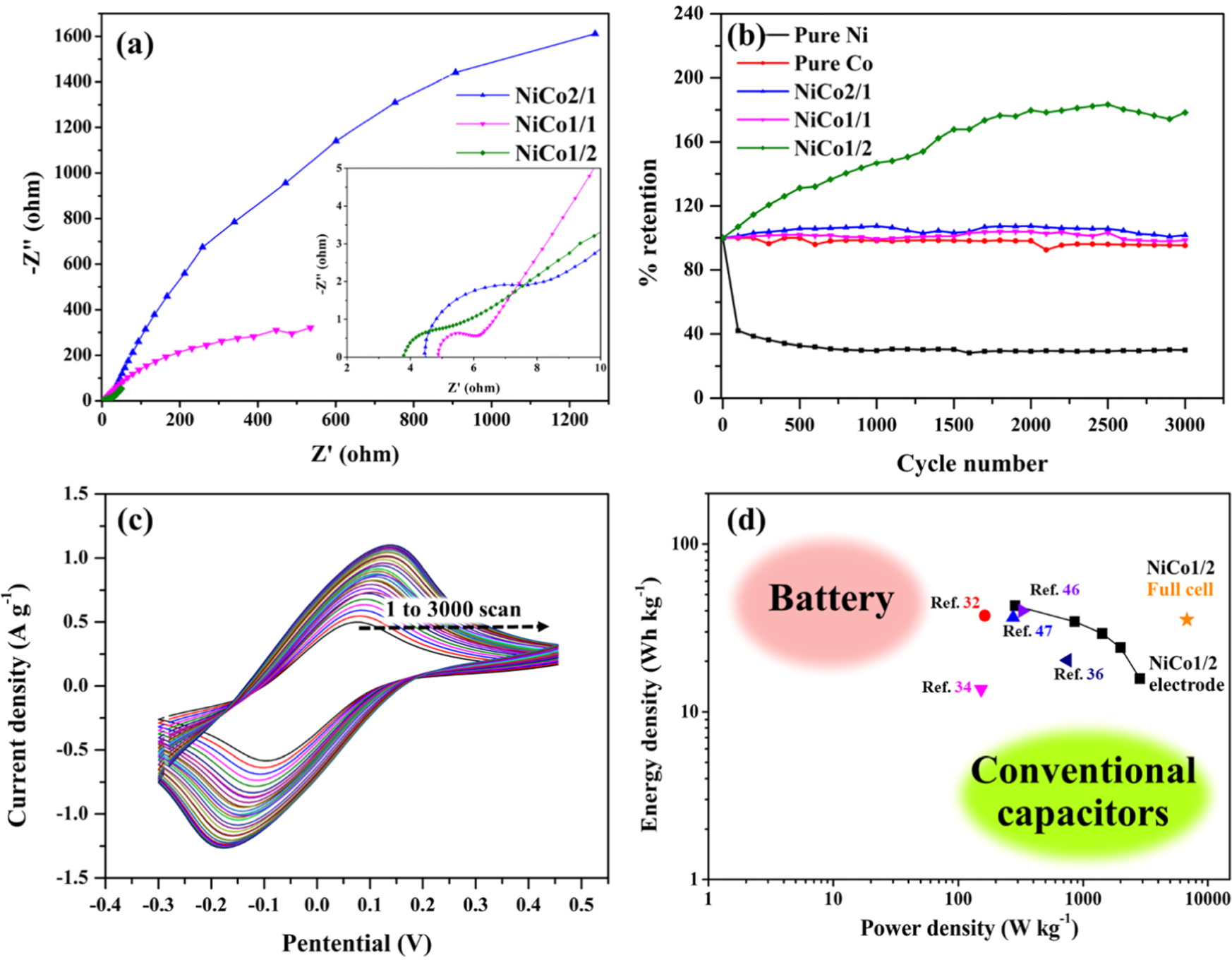

Figure 8. (a) Nyquist plots at a frequency range of $0.01-10000 \mathrm{~Hz}$ of different $\mathrm{Ni}-\mathrm{Co}$ carbonate hydroxides, (b) percent retention of different $\mathrm{Ni} / \mathrm{Co}$ ratios as a function of cycle number at a scan rate $40 \mathrm{mV} \mathrm{s}^{-1}$, (c) cyclic voltammograms of NiCo1/2 after 3000 cycles, and (d) ragone plots of $\mathrm{NiCo} 1 / 2$ and recent research for comparison.

confirming that the pseudocapacitive characteristic is participating in charge storage at a high rate for the nickel-cobalt carbonate hydroxide electrode. ${ }^{46}$

To evaluate the resistive nature of electrode samples, the comparative study of electrode samples at different $\mathrm{Ni} / \mathrm{Co}$ ratios using electrochemical impedance spectroscopic electrochemical impedance spectroscopy (EIS) analysis is investigated as shown in Figure 8a. The Nyquist plot is typically used to examine the terms of solution resistance $\left(R_{\mathrm{s}}\right)$, charge-transfer resistance $\left(R_{\mathrm{ct}}\right)$, and charge/ion mechanism diffusion in electrode materials. Nyquist plots of all electrode samples reveal two parts: a semicircular response between highintermediate frequency and a linear response at low frequency. In the region of high frequency, the initial resistance value of the semicircle region is referred to as the contact resistance between the interaction of active materials and electrolytes on the surface. The arc line intersection of semicircle portion from high-intermediate frequencies indicates the total resistance of electrode sample, corresponding to electron-transfer-limited processes. A relative linear range from middle to low frequency through phase angle corresponds with ion/charge diffusion into porous and interlayer of materials. ${ }^{47}$ Obviously, the increase of cobalt-to-nickel ratio trends to reduce the solution resistance $\left(R_{\mathrm{S}}\right)$ component in the low-frequency region, indicating the improvement of electrical capacitance behavior. Similarly, the semicircle region also tends to decrease with increasing cobalt proportion. Obviously, at Ni-to-Co ratio of $1: 2$, the electrode sample exhibits the lowest initial resistance value and impedance resistance value through phase angle, implying the highest ion/charge diffusion.

Figure $8 \mathrm{~b}$ demonstrates the comparative capacitance retention of all electrode samples from 1 to 3000 cycles. It is seen that pristine nickel carbonate hydroxide can preserve only $30.1 \%$ after 3000 cycles. Meanwhile, cobalt carbonate hydroxide exhibits retention constant of $100 \%$ after 500 cycles and a slight decrease to $95.4 \%$ after 3000 cycles. Thus, cobalt carbonate hydroxide is proven to possess a highly stable electrochemical performance compared with nickel carbonate hydroxide. Interestingly, all the nickel-cobalt carbonate hydroxide complex samples demonstrate better development of specific capacitance with increasing CV cycles than that of pristine nickel hydroxide and cobalt carbonate hydroxide. Especially, the retention of nickel-cobalt carbonate hydroxide at the $\mathrm{Ni} / \mathrm{Co}$ ratio of 1:2 can increase up to $178.3 \%$ after 3000 cycles, while the $\mathrm{Ni} / \mathrm{Co}$ ratio of $2: 1$ and $1: 1$ exhibit high stability at 101.7 and $98.6 \%$ after 3000 cycles. As the CV 
Table 2. Comparison of the Electrochemical Performance of the Nickel-Cobalt Carbonate Hydroxide at 1:2 Ratio with Performances in Other Reports

\begin{tabular}{|c|c|c|c|c|}
\hline material & electrolyte & specific capacitance & cycling stability & references \\
\hline nickel-cobalt carbonate hydroxide at 1:2 ratio (our work) & $6 \mathrm{M} \mathrm{KOH}$ & $950.2 \mathrm{~F} \mathrm{~g}^{-1}$ at $1 \mathrm{~A} \mathrm{~g}^{-1}$ & $178.3 \%$ at 3000 cycles & this work \\
\hline carbon cloth@CoCH@NiCoDLH & $2 \mathrm{M} \mathrm{KOH}$ & $7.71 \mathrm{~F} \mathrm{~cm}^{-2}$ at $10 \mathrm{~mA} \mathrm{~cm}^{-2}$ & $82.6 \%$ at 5000 cycles & 1 \\
\hline $\mathrm{Co}_{3} \mathrm{O}_{4}$ nanotubes & $6 \mathrm{M} \mathrm{KOH}$ & $574 \mathrm{~F} \mathrm{~g}^{-1}$ at $0.1 \mathrm{~A} \mathrm{~g}^{-1}$ & $95 \%$ at 1000 cycles & 50 \\
\hline $\mathrm{Co}_{3} \mathrm{O}_{4}$ thin film & $1 \mathrm{M} \mathrm{KOH}$ & $165 \mathrm{~F} \mathrm{~g}^{-1}$ at $10 \mathrm{mV} \mathrm{s}^{-1}$ & $98.3 \%$ at 1000 cycles & 51 \\
\hline $\mathrm{Co}_{3} \mathrm{O}_{4}$ nanowires & $6 \mathrm{M} \mathrm{KOH}$ & $746 \mathrm{~F} \mathrm{~g}^{-1}$ at $5 \mathrm{~mA} \mathrm{~cm}^{-2}$ & $86 \%$ at 500 cycles & 52 \\
\hline hierarchical porous nickel-cobalt oxides & $2 \mathrm{M} \mathrm{KOH}$ & $867.3 \mathrm{~F} \mathrm{~g}^{-1}$ at $1 \mathrm{~A} \mathrm{~g}^{-1}$ & $212 \%$ at 1000 cycles & 48 \\
\hline flower-like nickel-cobalt oxides & $2 \mathrm{M} \mathrm{KOH}$ & $750 \mathrm{~F} \mathrm{~g}^{-1}$ at $1 \mathrm{~A} \mathrm{~g}^{-1}$ & $86.4 \%$ at 10000 cycles & 31 \\
\hline aligned nickel-cobalt hydroxide nanorod & $1 \mathrm{M} \mathrm{KOH}$ & $456 \mathrm{~F} \mathrm{~g}^{-1}$ at $20 \mathrm{mV} \mathrm{s}^{-1}$ & $91 \%$ at 1000 cycles & 53 \\
\hline monodisperse b-phase $\mathrm{Co}(\mathrm{OH})_{2}$ nanowires & $6 \mathrm{M} \mathrm{KOH}$ & $358 \mathrm{~F} \mathrm{~g}^{-1}$ at $0.5 \mathrm{~A} \mathrm{~g}^{-1}$ & $86.3 \%$ at 5000 cycles & 49 \\
\hline sea-urchin-like porous $\mathrm{NiCo}_{2} \mathrm{O}_{4}$ spinel & $1 \mathrm{M} \mathrm{KOH}$ & $658 \mathrm{~F} \mathrm{~g}^{-1}$ at $1 \mathrm{~A} \mathrm{~g}^{-1}$ & $92.1 \%$ at 1000 cycles & 54 \\
\hline hierarchical nanoporous nickel/nickel hydroxide & $1 \mathrm{M} \mathrm{KOH}$ & $4.76 \mathrm{~F} \mathrm{~cm}^{-2}$ at $6.25 \mathrm{~mA} \mathrm{~cm}{ }^{-2}$ & $97 \%$ at 2000 cycles & 55 \\
\hline $\mathrm{NiCo}_{2} \mathrm{O}_{4}$ nanoparticles & $2 \mathrm{M} \mathrm{KOH}$ & $720.04 \mathrm{~F} \mathrm{~g}^{-1}$ at $1 \mathrm{~A} \mathrm{~g}^{-1}$ & $97.3 \%$ at 2000 cycles & 56 \\
\hline (1-D) wire-like $\mathrm{NiO} / \mathrm{Co}_{3} \mathrm{O}_{4}$ & $2 \mathrm{M} \mathrm{KOH}$ & $187 \mathrm{~F} \mathrm{~g}^{-1}$ at $1 \mathrm{~A} \mathrm{~g}^{-1}$ & $120 \%$ at 1500 cycles & 57 \\
\hline graphene $/ \mathrm{Co}_{3} \mathrm{O}_{4} /$ polypyrrole & $6 \mathrm{M} \mathrm{KOH}$ & $385 \mathrm{~F} \mathrm{~g}^{-1}$ at $1 \mathrm{~A} \mathrm{~g}^{-1}$ & & 58 \\
\hline nickel carbonate hydroxide/ zeolitic imidazolate & $6 \mathrm{M} \mathrm{KOH}$ & $851 \mathrm{~F} \mathrm{~g}^{-1}$ at $5 \mathrm{mV} \mathrm{s}^{-1}$ & & 59 \\
\hline
\end{tabular}
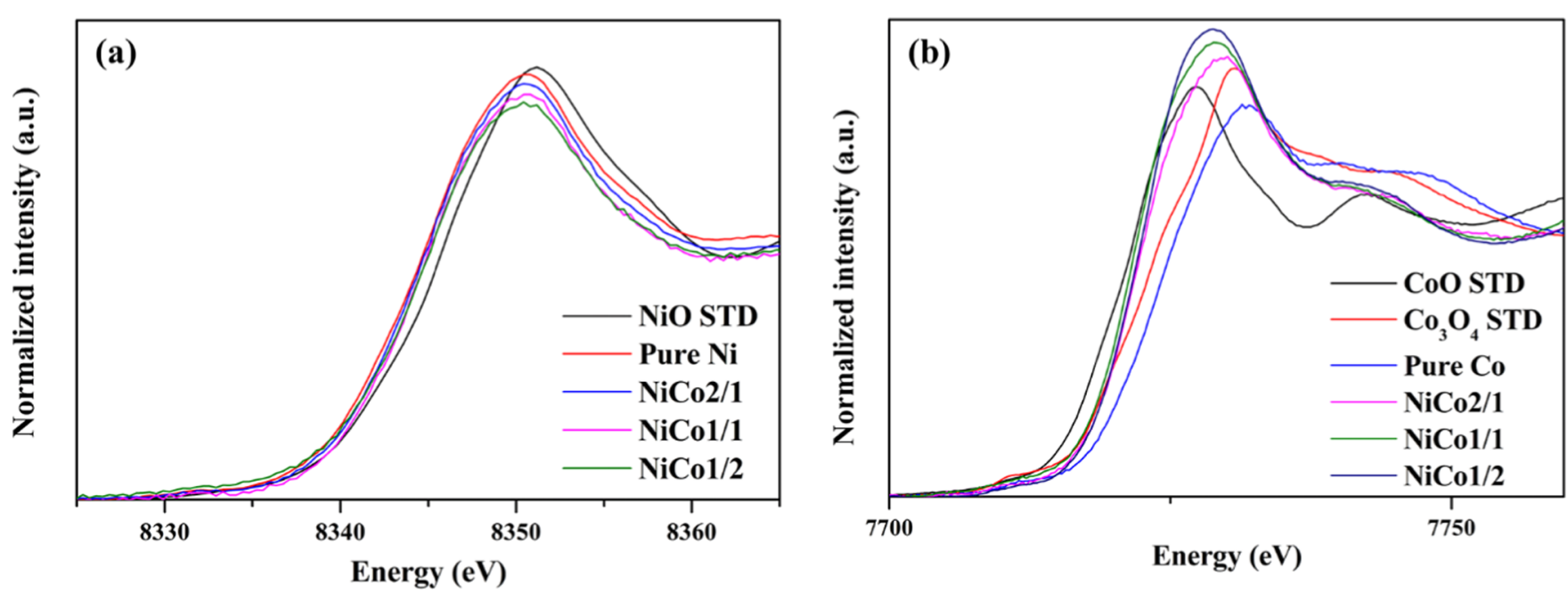

Figure 9. Comparison of XANES data of different Ni/Co ratios with element standard: (a) nickel part and (b) cobalt part.

evidence supports cycle stability for the nickel-cobalt carbonate hydroxide at the $\mathrm{Ni} / \mathrm{Co}$ ratio of $1: 2$ in Figure 8c, the current density of pair redox peak is dramatically increased with the CV cycles, suggesting that the development of phase crystallinity of the nickel-cobalt carbonate hydroxide during the charging-discharging cycles. This phenomenon is attributed to the formation of intermediate cobalt carbonate hydroxide spices during the redox reaction, which increases the phase crystallinity of cobalt carbonate hydroxide, leading to an increase in faradic reaction. Furthermore, the performance of the nickel-cobalt carbonate hydroxide electrode at the $\mathrm{Ni} / \mathrm{Co}$ ratio of $1: 2$ is compared with those of the other nickel-cobalt SCs sources as seen in the ragone plot of Figure $8 \mathrm{~d}$. The energy density and power density are calculated as eqs 8,9 , respectively. The nickel-cobalt carbonate hydroxide electrode at the $\mathrm{Ni} / \mathrm{Co}$ ratio of $1: 2$ can yield an energy density in the range of $42.9-15.8 \mathrm{Wh} \mathrm{kg}^{-1}$, while the power density values are in the range of $285.0-2849.9 \mathrm{~W} \mathrm{~kg}^{-1}$. In addition, the energy density and power density of the $\mathrm{NiCo} 1 / 2$ symmetric cell are $35.4 \mathrm{Wh} \mathrm{kg}^{-1}$ at $6797.25 \mathrm{~W} \mathrm{~kg}$. This result demonstrates a much higher value than those of conventional capacitors and many reports of nickel-cobalt materials. $^{32,36,40,48,49}$ A comparison of the electrochemical performance of the NiCo1:2 sample with other reports is also illustrated in Table 2. Apparently, our study shows an outstanding electrocapacitance performance compared to other reports.

To investigate the valence state of the as-prepared $\mathrm{Ni}-\mathrm{Co}$ carbonate hydroxide samples at different $\mathrm{Ni} / \mathrm{CO}$ ratios, further analysis by X-ray absorption near-edge structure (XANES) technique is employed. The individual $\mathrm{K}$ energy of nickel and cobalt is separately monitored with $\mathrm{NiO}, \mathrm{CoO}$, and $\mathrm{Co}_{3} \mathrm{O}_{4}$ standard, representing $\mathrm{Ni}^{2+}, \mathrm{Co}^{2+}$, and $\mathrm{Co}^{3+}$ ion, respectively. The absorption K-edge of $\mathrm{Ni}$ and $\mathrm{Co}$ for the as-prepared $\mathrm{Ni}-$ Co carbonate hydroxide samples at different $\mathrm{Ni} / \mathrm{Co}$ ratios is revealed in Figure 9a,b, respectively. As seen in Figure 9a, the absorption K-edge of the as-prepared nickel carbonate hydroxide is nearly close to that of $\mathrm{NiO}$ standard, suggesting the same valence of $\mathrm{Ni}^{+2}$. All nickel-cobalt carbonate hydroxide samples exhibit nearly close to K-edge energy of $\mathrm{NiO}$ standard, indicating that all nickel-cobalt carbonate hydroxide samples exhibit $\mathrm{Ni}^{2+}$ ion in nickel part. In other words, the formation of $\mathrm{Ni}$ valence states does not interfere with the incorporation of cobalt during the hydrothermal process. Furthermore, the white line peak intensities of the $\mathrm{Ni}-\mathrm{Co}$ carbonate hydroxide are slightly decreased with the decreasing nickel contents, implying the increase in the local disorder of the nearest neighbors of the Ni bulk. ${ }^{60}$ 


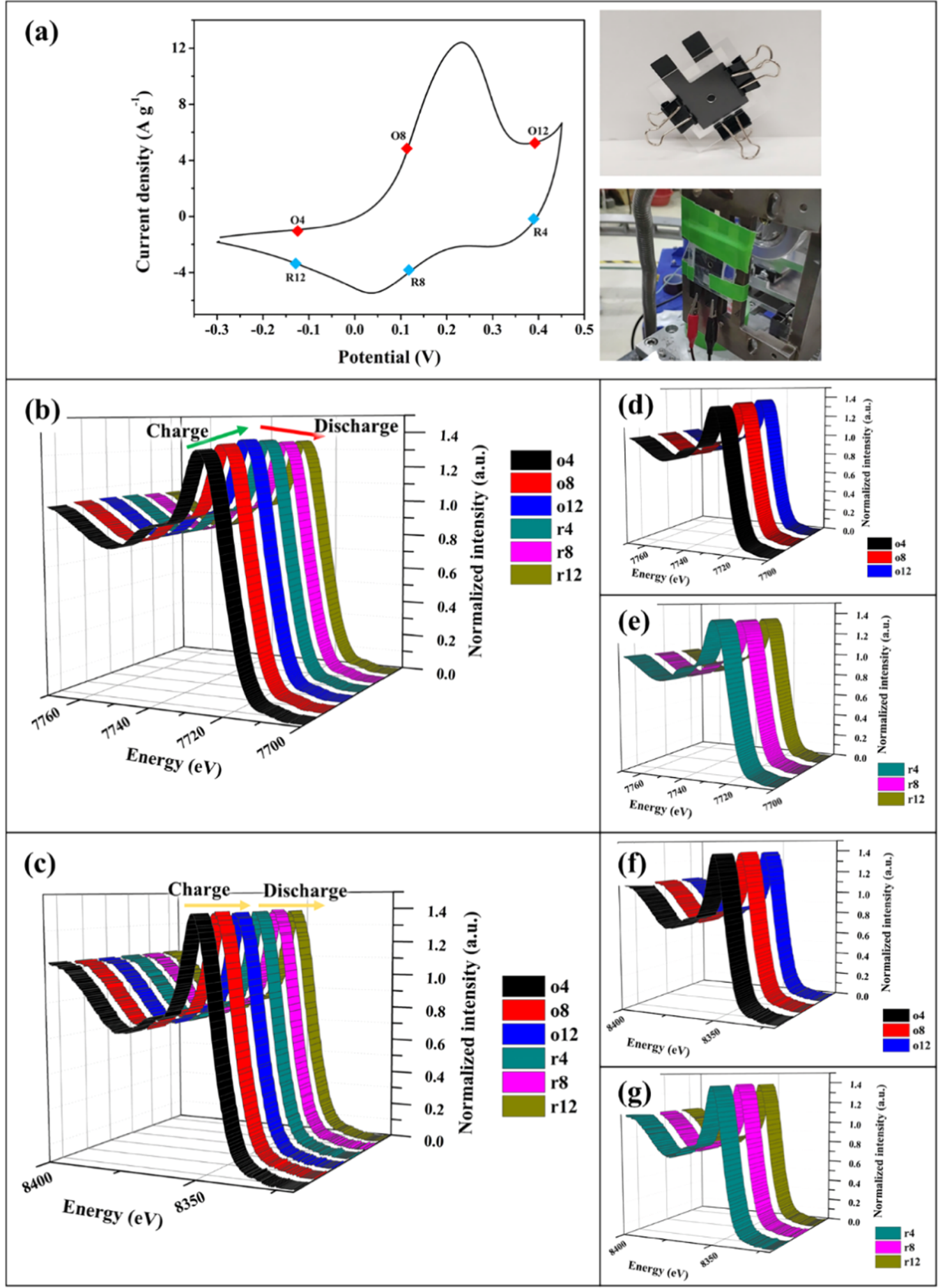

Figure 10. (a) Schematic of XANES collecting point on cyclic voltammetry curve at $1 \mathrm{mV} \mathrm{s}^{-1}$ and the experimental cell of TR-XAS measuring; comparison of in situ XANES collected of NiCol/2 on CV measuring. full cycle in (b) Co and (c) Ni part. (d) Charge and (e) discharge of Co part. (f) Charge and (g) discharge of Ni part.

For the absorption K-edge of cobalt (Figure 9b), the K-edge energy of the as-prepared cobalt carbonate hydroxide is nearly close to that of the $\mathrm{Co}_{3} \mathrm{O}_{4}$ standard, suggesting the valence of $\mathrm{Co}^{2+}$ and $\mathrm{Co}^{3+}$. Meanwhile, all as-prepared nickel-cobalt carbonate hydroxide samples at different $\mathrm{Ni} / \mathrm{Co}$ ratios exhibit the shift of K-edge energy and are close to $\mathrm{CoO}$ when it is hydrothermally synthesized with nickel. These results indicate the formation of diverse Co-valence states of +2 and +3 . The K-edge energy also shows a lower shift in intensity with cobalt content, implying the Co-valence state is nearly close to $\mathrm{Co}^{2+}$. 
The white line peak intensity of cobalt bulk for the Ni-Co carbonate hydroxide complex reveals an increase with cobalt content, implying the decrease in the local disorder of the nearest-neighbor atom of the Co bulk. ${ }^{61}$

To understand the charge-discharge mechanism, the optimized sample at $\mathrm{Ni} / \mathrm{Co}$ ratio of $1: 2$ is further investigated the change of valence behavior during $\mathrm{CV}$ cycling at $1 \mathrm{mV} \mathrm{s}^{-1}$. Figure 10a shows that the asymmetrical cell of nickel-cobalt carbonate hydroxide is fabricated and monitored with the XANES technique at each CV measurement point. The in situ XANES spectra of $\mathrm{Co}$ and $\mathrm{Ni}$ signal for an overall chargedischarge cycle (as well as charge-discharge) are monitored as revealed in Figure 10b,c, respectively. The separated plots for Co- and Ni-charging from -0.3 to $0.45 \mathrm{~V}$ are presented in Figure $10 \mathrm{~d}, \mathrm{f}$, respectively. While the separated plot for Co- and $\mathrm{Ni}$-discharging from 0.45 to $-0.3 \mathrm{~V}$ are exhibited in Figure $10 \mathrm{e}, \mathrm{g}$, respectively. Obviously, the white line peak of Co demonstrates the gradual increment during the charging process. Subsequently, a slight decrease in the white line peak intensity of Co is observed during discharge, as shown in Figure 10d,e. However, no significant change in the white line of $\mathrm{Ni}$ is observed during the charge-discharge process (Figure 10f,g). These results imply that the high performance of the capacitive behavior in the nickel-cobalt carbonate hydroxide is mainly dominated by cobalt carbonate hydroxide. In addition, it is seen that the white line of Co after the oxidationreduction cycle does not turn back to the original state but retains the positive state, implying the occurrence of the phase development of cobalt carbonate hydroxide through cycling. This result reveals the corresponding agreement with cycling stability, demonstrating the increment of specific capacitance after a long charge-discharge cycle.

\section{CONCLUSIONS}

To summarize, the nickel-cobalt carbonate hydroxide with a 3D sea-urchin-like structure is successfully synthesized by the facile hydrothermal process. The morphology of the synthesized binary carbonate hydroxide, which progresses from needle and nanoflower structures to sea-urchin-like structures, is highly controllable by adjusting the Ni-to-Co mole ratio. Nickel-cobalt carbonate hydroxide has the highest specific capacitance value of $950.2 \mathrm{~F} \mathrm{~g}^{-1}$ at an optimized $\mathrm{Ni}$ / Co ratio of 1 to 2 . Conforming with XANES, the battery-like behavior of nickel-cobalt carbonate hydroxide capacitive electrode is mainly dominated by cobalt carbonate hydroxide. The symmetric supercapacitor device exhibits excellent cycling stability ( $178.3 \%$ after 3000 cycles). The energy density is in the range of $42.9-15.8 \mathrm{Wh} \mathrm{kg}^{-1}$ at a power density of $285.0-$ $2849.9 \mathrm{~W} \mathrm{~kg}^{-1}$.

\section{EXPERIMENTAL PROCEDURES}

4.1. Chemicals. Nickel(II) nitrate hexahydrate ( $\geq 97.0 \%)$ was obtained from Sigma-Aldrich. Cobalt(II) nitrate hexahydrate $(\geq 97.0 \%)$ was purchased from Ajax Finechem. Other reagents were analytical grade and used as received without any further purification.

4.2. Nickel-Cobalt Carbonate Hydroxide Synthesis. Initially, $0.5 \mathrm{M}$ nickel nitrate hexahydrate and $0.5 \mathrm{M}$ cobalt nitrate hexahydrate were mixed by controlling the total volume of $50 \mathrm{~mL}$ until the solid disappears. Then, $1.31 \mathrm{~g}(1.0 \mathrm{mmol})$ of hexamethylenetetramine (HMTA) and $0.52 \mathrm{~g}(1.8 \mathrm{mmol})$ of sodium dodecyl sulfate (SDS) were added and stirred until a homogeneous solution was produced. The solution was transferred into a $100 \mathrm{~mL}$ Teflon autoclave. The hydrothermal reaction was conducted at $140{ }^{\circ} \mathrm{C}$ for $14 \mathrm{~h}$. After that, the obtained solid sample was washed several times with DI water and dried at $60{ }^{\circ} \mathrm{C}$ for $24 \mathrm{~h}$. The different mole ratios of $\mathrm{Ni} / \mathrm{Co}$ were also prepared at 1:0, 2:1, 1:1, 1:2, and $0: 1$ with the aforementioned method by controlling the total volume of the metal salt solution.

4.3. Preparation of Working Electrode Samples. Working electrode samples were prepared by mixing $80 \mathrm{wt}$ $\%$ of active materials, 15 wt $\%$ of carbon black, and 5 wt $\%$ of poly(tetrafluoroethylene)s (PTFE). The solid mixture was mixed with ethanol to obtain a slurry mixture and coated on carbon fiber paper $\left(1 \times 1 \mathrm{~cm}^{2}\right)$. The total weight of the solid mixture was controlled at approximately $1.0 \mathrm{mg} \mathrm{cm}^{-2}$ for all coated materials.

4.4. Electrochemical Characterization. The electrode samples were measured the electrochemical properties by the potentiostat/galvanostat instrument (Metrohm Autolab, PGSTAT204, Netherlands) to investigate cyclic voltammetry (CV), galvanostatic charge-discharge (GCD), and electrochemical impedance spectroscopy (EIS). The three-electrode system was used in a $6 \mathrm{M} \mathrm{KOH}$ electrolyte support solution and configured with active materials, platinum plate, and $\mathrm{Ag} /$ $\mathrm{AgCl}$ as the working electrodes, counter electrodes, and reference electrodes, respectively. $\mathrm{CV}$ was employed with a potential of -0.3 to $0.45 \mathrm{~V}$ at scan rates from 10 to $100 \mathrm{mV}$ $\mathrm{s}^{-1}$. GCD was examined at -0.2 to $0.37 \mathrm{~V}$ at the current density from 1 to $10 \mathrm{~A} \mathrm{~g}^{-1}$. EIS was performed in $1 \mathrm{M} \mathrm{KOH}$ at the voltage of $5 \mathrm{mV}$ over a frequency range from $0.01 \mathrm{~Hz}$ to $100 \mathrm{kHz}$. In addition, the symmetrical cell using a CR2032 coin cell was fabricated to measure the cycle stability performance. Two electrodes of $\mathrm{NiCol} / 2$ are sandwiched together with a glass fiber separator and $6 \mathrm{M} \mathrm{KOH}$ as electrolyte. The cycle stability testing was conducted by $\mathrm{CV}$ technique at a scan rate of $40 \mathrm{mV} \mathrm{s}^{-1}$ for 3000 cycles using a potentiostat/galvanostat instrument (Metrohm Autolab, PGSTAT204, Netherlands). The specific capacitance $\left(C_{s p}\right)$ is calculated from the GCD result following eq 7. The energy density $(E)$ and the power density $(P)$ are calculated from eqs 8 and 9.

$$
\begin{aligned}
& C_{\mathrm{sp}}=\frac{I(t)}{m(\Delta V)} \\
& E=\frac{1}{2} C_{\mathrm{sp}}(\Delta V)^{2} \\
& P=E / T
\end{aligned}
$$

where $I$ is the constant discharge current (A), $t$ is the discharging time (s), $m$ is the mass of active material sample (g), $\Delta \mathrm{V}$ is the window potential $(\mathrm{V})$, and $T$ is discharging time (h).

4.5. Characterization. X-ray diffraction (XRD, Bruker D8 Advance) was performed using $\mathrm{Cu} \mathrm{K} \alpha$ radiation to observe the crystal structure of the samples. A scanning electron microscope equipped with an energy-dispersive X-ray spectrometer (SEM-EDS, JEOL JSM-IT500HR, Japan) was used to observe the sample morphology and analyze the surface element of samples. The BET surface area and porosity parameter were performed using nitrogen gas adsorption/desorption isotherm measurements (Micromeritics 3 Flex 3500). X-ray photoelectron spectroscopy (XPS; AXIS ultra DLD, U.K.) was 
performed to investigate the chemical states of samples. Timeresolved X-ray absorption spectroscopy (TR-XAS, beamline 2.2 at Synchrotron Light Research Institute (SLRI), Thailand) was carried out with the absorption edge energy at 8333 and $7709 \mathrm{eV}$ to detect nickel and cobalt elements, respectively. The transmission mode was performed to investigate the X-ray absorption near-edge structure (XANES) of sample side electrode during charging and discharging. The chargedischarge process was performed by $\mathrm{CV}$ technique at scan rate of $1 \mathrm{mV} \mathrm{s}^{-1}$. Asymmetric supercapacitors (ASCs) assembled using two dissimilar electrode was fabricated using the sample electrode as the cathode, the carbon fiber paper as the anode, and filter paper separator with $6.0 \mathrm{M} \mathrm{KOH}$ electrolyte.

\section{ASSOCIATED CONTENT}

\section{SI Supporting Information}

The Supporting Information is available free of charge at https://pubs.acs.org/doi/10.1021/acsomega.1c02139.

Experimental details of the materials (XPS, BET, and EIS circuit fitting) (PDF)

\section{AUTHOR INFORMATION}

\section{Corresponding Authors}

Prasit Pattananuwat - Department of Materials Science, Faculty of Science, Chulalongkorn University, Bangkok 10330, Thailand; Research Unit of Advanced Materials for Energy Storage and Center of Excellence on Petrochemical and Materials Technology, Chulalongkorn University, Bangkok 10330, Thailand; Email: prasit.pat@chula.ac.th

Pranut Potiyaraj - Department of Materials Science, Faculty of Science, Chulalongkorn University, Bangkok 10330, Thailand; Center of Excellence on Petrochemical and Materials Technology and Center of Excellence on Responsive Wearable Materials, Chulalongkorn University, Bangkok 10330, Thailand; 이이.org/0000-0002-9114-9155; Email: pranut.p@chula.ac.th

\section{Author}

Nutthapong Poompiew - Department of Materials Science, Faculty of Science, Chulalongkorn University, Bangkok 10330, Thailand

Complete contact information is available at: https://pubs.acs.org/10.1021/acsomega.1c02139

\section{Notes}

The authors declare no competing financial interest.

\section{ACKNOWLEDGMENTS}

This research was supported by the 90th Anniversary of Chulalongkorn University (Ratchadaphiseksomphot Endowment Fund). The authors would like to thank Dr. Wanwisa Limphirat from Synchrotron Light Research Institute (SLRI), Nakhon Ratchasima, Thailand, for TR-XAS knowledge skill, laboratory facility, and instrumental support.

\section{REFERENCES}

(1) Li, Y.; Wang, L.; Qu, Y.; Wang, B.; Yu, J.; Song, D.; Duan, C.; Yang, Y. Unique 3D bilayer nanostructure basic cobalt carbonate@ $\mathrm{NiCo}$-layered double hydroxide nanosheets on carbon cloth for supercapacitor electrode material. Ionics 2020, 26, 1397-1406.
(2) Lin, Z.; Shen, S.; Wang, Z.; Zhong, W. Laser ablation in air and its application in catalytic water splitting and Li-ion battery. iScience 2021, 24, No. 102469.

(3) Li, G.; Ouyang, T.; Xiong, T.; Jiang, Z.; Adekoya, D.; Wu, Y.; Huang, Y.; Balogun, M. S. All-carbon-frameworks enabled thick electrode with exceptional high-areal-capacity for Li-Ion storage. Carbon 2021, 174, 1-9.

(4) Zhou, S.; Huang, P.; Xiong, T.; Yang, F.; Yang, H.; Huang, Y.; Li, D.; Deng, J.; Balogun, M. J. T. Sub-Thick Electrodes with Enhanced Transport Kinetics via In Situ Epitaxial Heterogeneous Interfaces for High Areal-Capacity Lithium Ion Batteries. Small 2021, 17, No. e2100778.

(5) Huang, Y.; Yang, H.; Xiong, T.; Adekoya, D.; Qiu, W.; Wang, Z.; Zhang, S.; Balogun, M. S. Adsorption energy engineering of nickel oxide hybrid nanosheets for high areal capacity flexible lithium-ion batteries. Energy Storage Mater. 2020, 25, 41-51.

(6) Yang, T.; Ye, Q.; Liang, Y.; Wu, L.; Long, X.; Xu, X.; Wang, F. Graded holey Nickel Cobalt layered double hydroxide nanosheet array electrode with high mass loading for high-energy-density allsolid-state supercapacitors. J. Power Sources 2020, 449, No. 227590.

(7) Li, L.; Song, H.; Zhang, Q.; Yao, J.; Chen, X. Effect of compounding process on the structure and electrochemical properties of ordered mesoporous carbon/polyaniline composites as electrodes for supercapacitors. J. Power Sources 2009, 187, 268-274.

(8) Pattananuwat, P.; Aht-ong, D. Controllable morphology of polypyrrole wrapped graphene hydrogel framework composites via cyclic voltammetry with aiding of poly (sodium 4-styrene sulfonate) for the flexible supercapacitor electrode. Electrochim. Acta 2017, 224, $149-160$.

(9) Sharma, R. K.; Rastogi, A. C.; Desu, S. B. Manganese oxide embedded polypyrrole nanocomposites for electrochemical supercapacitor. Electrochim. Acta 2008, 53, 7690-7695.

(10) Zhong, W.; Xiao, B.; Lin, Z.; Wang, Z.; Huang, L.; Shen, S.; Zhang, Q.; Gu, L. RhSe2: A Superior 3D Electrocatalyst with Multiple Active Facets for Hydrogen Evolution Reaction in Both Acid and Alkaline Solutions. Adv. Mater. 2021, 33, No. e2007894.

(11) Wang, G.-X.; Zhang, B.-L.; Yu, Z.-L.; Qu, M.-Z. Manganese oxide/MWNTs composite electrodes for supercapacitors. Solid State Ionics 2005, 176, 1169-1174.

(12) Xiong, T.; Su, H.; Yang, F.; Tan, Q.; Appadurai, P. B. S.; Afuwape, A. A.; Guo, K.; Huang, Y.; Wang, Z.; Balogun, M. S. Harmonizing self-supportive VN/MoS2 pseudocapacitance core-shell electrodes for boosting the areal capacity of lithium storage. Mater. Today Energy 2020, 17, No. 100461.

(13) Babu, R. S.; de Barros, A. L. F.; de Almeida Maier, M.; da Motta Sampaio, D.; Balamurugan, J.; Lee, J. H. Novel polyaniline/ manganese hexacyanoferrate nanoparticles on carbon fiber as binder-free electrode for flexible supercapacitors. Composites, Part B 2018, 143, 141-147.

(14) Su, H.; Wang, T.; Zhang, S.; Song, J.; Mao, C.; Niu, H.; Jin, B.; $\mathrm{Wu}, \mathrm{J}$; Tian, Y. Facile synthesis of polyaniline/TiO2/graphene oxide composite for high performance supercapacitors. Solid State Sci. 2012, $14,677-681$

(15) Asen, P.; Shahrokhian, S.; Iraji zad, A. One step electrodeposition of $\mathrm{V} 2 \mathrm{O} 5$ /polypyrrole/graphene oxide ternary nanocomposite for preparation of a high performance supercapacitor. Int. J. Hydrogen Energy 2017, 42, 21073-21085.

(16) Wu, M.-S.; Lyu, L.-J.; Syu, J.-H. Copper and nickel hexacyanoferrate nanostructures with graphene-coated stainless steel sheets for electrochemical supercapacitors. J. Power Sources 2015, 297, $75-82$.

(17) Wang, Z.; Lin, Z.; Deng, J.; Shen, S.; Meng, F.; Zhang, J.; Zhang, Q.; Zhong, W.; Gu, L. Elevating the d-Band Center of SixCoordinated Octahedrons in $\mathrm{Co}_{9} \mathrm{~S}_{8}$ through Fe-Incorporated Topochemical Deintercalation. Adv. Energy Mater. 2020, 11, No. 2170020.

(18) Zhong, W.; Wang, Z.; Gao, N.; Huang, L.; Lin, Z.; Liu, Y.; Meng, F.; Deng, J.; Jin, S.; Zhang, Q.; Gu, L. Coupled Vacancy Pairs in $\mathrm{Ni}$-Doped $\mathrm{CoSe}$ for Improved Electrocatalytic Hydrogen 
Production Through Topochemical Deintercalation. Angew. Chem., Int. Ed. 2020, 59, 22743-22748.

(19) Shen, S.; Lin, Z.; Song, K.; Wang, Z.; Huang, L.; Yan, L.; Meng, F.; Zhang, Q.; Gu, L.; Zhong, W. Reversed Active Sites Boost the Intrinsic Activity of Graphene-like Cobalt Selenide for Hydrogen Evolution. Angew. Chem., Int. Ed. 2021, 60, 12360-12365.

(20) Xiong, P.; Huang, H.; Wang, X. Design and synthesis of ternary cobalt ferrite/graphene/polyaniline hierarchical nanocomposites for high-performance supercapacitors. J. Power Sources 2014, 245, 937946.

(21) Zhong, W.; Huang, X.; Lin, Y.; Cao, Y.; Wang, Z. Compact Co3O4/Co in-situ nanocomposites prepared by pulsed laser sintering as anode materials for lithium-ion batteries. J. Energy Chem. 2021, 58, 386-390.

(22) Wen, S.; Qin, K.; Liu, P.; Zhao, N.; Shi, C.; Ma, L.; Liu, E. Ultrafine $\mathrm{Ni}(\mathrm{OH}) 2$ nanoneedles on $\mathrm{N}$-doped 3D rivet graphene film for high-performance asymmetric supercapacitor. J. Alloys Compd. 2019, 783, 625-632.

(23) Wang, H.; Holt, C. M. B.; Li, Z.; Tan, X.; Amirkhiz, B. S.; Xu, Z.; Olsen, B. C.; Stephenson, T.; Mitlin, D. Graphene-nickel cobaltite nanocomposite asymmetrical supercapacitor with commercial level mass loading. Nano Res. 2012, 5, 605-617.

(24) Martins, P. R.; Araújo Parussulo, A. L.; Toma, S. H.; Rocha, M. A.; Toma, H. E.; Araki, K. Highly stabilized alpha-NiCo $(\mathrm{OH}) 2$ nanomaterials for high performance device application. J. Power Sources 2012, 218, 1-4.

(25) Wang, R.; Yan, X. Superior asymmetric supercapacitor based on Ni-Co oxide nanosheets and carbon nanorods. Sci. Rep. 2015, 4, No. 3712.

(26) Karthik, N.; Edison, T. N. J. I.; Atchudan, R.; Xiong, D.; Lee, Y. R. Electro-synthesis of sulfur doped nickel cobalt layered double hydroxide for electrocatalytic hydrogen evolution reaction and supercapacitor applications. J. Electroanal. Chem. 2019, 833, 105-112.

(27) Ebrahim, S. A.; Harb, M. E.; Soliman, M. M.; Tayel, M. B. Preparation and characterization of a pseudocapacitor electrode by spraying a conducting polymer onto a flexible substrate. J. Taibah Univ. Sci. 2016, 10, 281-285.

(28) Dong, X.-C.; Xu, H.; Wang, X.-W.; Huang, Y.-X.; Chan-Park, M. B.; Zhang, H.; Wang, L.-H.; Huang, W.; Chen, P. 3D GrapheneCobalt Oxide Electrode for High-Performance Supercapacitor and Enzymeless Glucose Detection. ACS Nano 2012, 6, 3206-3213.

(29) Song, S.; Zhang, L.; Shi, H. 3D nickel-cobalt double hydroxides nanosheets in situ grown on nitrogen-containing activated carbon for high-performance electrode materials. J. Alloys Compd. 2019, 779, $59-66$.

(30) Zhang, G.; David Lou, X. W. Controlled growth of $\mathrm{NiCo}(2) \mathrm{O}(4)$ nanorods and ultrathin nanosheets on carbon nanofibers for high-performance supercapacitors. Sci. Rep. 2013, 3, No. 1470 .

(31) Zhang, J.; Liu, F.; Cheng, J. P.; Zhang, X. B. Binary NickelCobalt Oxides Electrode Materials for High-Performance Supercapacitors: Influence of its Composition and Porous Nature. ACS Appl. Mater. Interfaces 2015, 7, 17630-17640.

(32) Wang, X.; Yan, C.; Sumboja, A.; Lee, P. S. High performance porous nickel cobalt oxide nanowires for asymmetric supercapacitor. Nano Energy 2014, 3, 119-126.

(33) Kumar, K. V.; Gadipelli, S.; Wood, B.; Ramisetty, K. A.; Stewart, A. A.; Howard, C. A.; Brett, D. J. L.; Rodriguez-Reinoso, F. Characterization of the adsorption site energies and heterogeneous surfaces of porous materials. J. Mater. Chem. A 2019, 7, 1010410137.

(34) Lee, D.; Xia, Q. X.; Yun, J. M.; Kim, K. H. High-performance cobalt carbonate hydroxide nano-dot $/ \mathrm{NiCo}(\mathrm{CO} 3)(\mathrm{OH}) 2$ electrode for asymmetric supercapacitors. Appl. Surf. Sci. 2018, 433, 16-26.

(35) Bhojane, P.; Sinha, L.; Goutam, U. K.; Shirage, P. M. A 3D mesoporous flowers of nickel carbonate hydroxide hydrate for highperformance electrochemical energy storage application. Electrochim. Acta 2019, 296, 112-119.
(36) Zhong, Y.; Cao, X.; Liu, Y.; Cui, L.; Liu, J. Nickel cobalt manganese ternary carbonate hydroxide nanoflakes branched on cobalt carbonate hydroxide nanowire arrays as novel electrode material for supercapacitors with outstanding performance. J. Colloid Interface Sci. 2021, 581, 11-20.

(37) Karthick, K.; Subhashini, S.; Kumar, R.; Sethuram Markandaraj, S.; Teepikha, M. M.; Kundu, S. Cubic Nanostructures of NickelCobalt Carbonate Hydroxide Hydrate as a High-Performance Oxygen Evolution Reaction Electrocatalyst in Alkaline and Near-Neutral Media. Inorg. Chem. 2020, 16690-16702.

(38) Cao, X.; Liu, Y.; Zhong, Y.; Cui, L.; Zhang, A.; Razal, J. M.; Yang, W.; Liu, J. Flexible coaxial fiber-shaped asymmetric supercapacitors based on manganese, nickel co-substituted cobalt carbonate hydroxides. J. Mater. Chem. A 2020, 8, 1837-1848.

(39) Wei, Z.; Yuan, J.; Tang, S.; Wu, D.; Wu, L. Porous nanorods of nickel-cobalt double hydroxide prepared by electrochemical codeposition for high-performance supercapacitors. J. Colloid Interface Sci. 2019, 542, 15-22.

(40) Bera, A.; Maitra, A.; Das, A. K.; Halder, L.; Paria, S.; Si, S. K.; De, A.; Ojha, S.; Khatua, B. B. A Quasi-Solid-State Asymmetric Supercapacitor Device Based on Honeycomb-like Nickel-CopperCarbonate-Hydroxide as a Positive and Iron Oxide as a Negative Electrode with Superior Electrochemical Performances. ACS Appl. Electron. Mater. 2020, 2, 177-185.

(41) Jiao, L.; Pan, X.; Xi, Y.; Li, J.; Cao, J.; Guo, Q.; Han, W. A facile synthesis of self-assembling reduced graphene oxide/cobalt carbonate hydroxide papers for high-performance supercapacitor applications. J. Mater. Sci.: Mater. Electron. 2018, 30, 159-166.

(42) Li, R.; Hu, Z.; Shao, X.; Cheng, P.; Li, S.; Yu, W.; Lin, W.; Yuan, D. Large Scale Synthesis of NiCo Layered Double Hydroxides for Superior Asymmetric Electrochemical Capacitor. Sci. Rep. 2016, 6, No. 18737.

(43) Zou, Y.; Cai, C.; Xiang, C.; Huang, P.; Chu, H.; She, Z.; Xu, F.; Sun, L.; Kraatz, H.-B. Simple synthesis of core-shell structure of Co$\mathrm{Co3O} 4 @$ carbon-nanotube-incorporated nitrogen-doped carbon for high-performance supercapacitor. Electrochim. Acta 2018, 261, 537547.

(44) Ban, F. Y.; Jayabal, S.; Lim, H. N.; Lee, H. W.; Huang, N. M. Synthesis of nitrogen-doped reduced graphene oxide-multiwalled carbon nanotube composite on nickel foam as electrode for highperformance supercapacitor. Ceram. Int. 2017, 43, 20-27.

(45) Wan, F.; Zhang, L.; Dai, X.; Wang, X.; Niu, Z.; Chen, J. Aqueous rechargeable zinc/sodium vanadate batteries with enhanced performance from simultaneous insertion of dual carriers. Nat. Commun. 2018, 9, No. 1656.

(46) Lan, Y.; Zhao, H.; Zong, Y.; Li, X.; Sun, Y.; Feng, J.; Wang, Y.; Zheng, X.; Du, Y. Phosphorization boosts the capacitance of mixed metal nanosheet arrays for high performance supercapacitor electrodes. Nanoscale 2018, 10, 11775-11781.

(47) Bai, X.; Liu, Q.; Zhang, H.; Liu, J.; Li, Z.; Jing, X.; Yuan, Y.; Liu, L.; Wang, J. Nickel-Cobalt Layered Double Hydroxide Nanowires on Three Dimensional Graphene Nickel Foam for High Performance Asymmetric Supercapacitors. Electrochim. Acta 2016, 215, 492-499.

(48) Chang, J.; Sun, J.; Xu, C.; Xu, H.; Gao, L. Template-free approach to synthesize hierarchical porous nickel cobalt oxides for supercapacitors. Nanoscale 2012, 4, 6786-6791.

(49) Tang, Y.; Liu, Y.; Yu, S.; Mu, S.; Xiao, S.; Zhao, Y.; Gao, F. Morphology controlled synthesis of monodisperse cobalt hydroxide for supercapacitor with high performance and long cycle life. J. Power Sources 2014, 256, 160-169.

(50) Xu, J.; Gao, L.; Cao, J.; Wang, W.; Chen, Z. Preparation and electrochemical capacitance of cobalt oxide $(\mathrm{Co} 3 \mathrm{O} 4)$ nanotubes as supercapacitor material. Electrochim. Acta 2010, 56, 732-736.

(51) Kandalkar, S. G.; Gunjakar, J. L.; Lokhande, C. D. Preparation of cobalt oxide thin films and its use in supercapacitor application. Appl. Surf. Sci. 2008, 254, 5540-5544.

(52) Gao, Y.; Chen, S.; Cao, D.; Wang, G.; Yin, J. Electrochemical capacitance of $\mathrm{Co} 3 \mathrm{O} 4$ nanowire arrays supported on nickel foam. $J$. Power Sources 2010, 195, 1757-1760. 
(53) Salunkhe, R. R.; Jang, K.; Lee, S.-w.; Ahn, H. Aligned nickelcobalt hydroxide nanorod arrays for electrochemical pseudocapacitor applications. RSC Adv. 2012, 2, No. 3190.

(54) Xiao, J.; Yang, S. Sequential crystallization of sea urchin-like bimetallic $(\mathrm{Ni}, \mathrm{Co})$ carbonate hydroxide and its morphology conserved conversion to porous $\mathrm{NiCo} 2 \mathrm{O} 4$ spinel for pseudocapacitors. RSC Adv. 2011, 1, No. 588.

(55) Qiu, H. J.; Peng, L.; Li, X.; Wang, Y. Enhanced supercapacitor performance by fabricating hierarchical nanoporous nickel/nickel hydroxide structure. Mater. Lett. 2015, 158, 366-369.

(56) Zhu, Y.; Chen, J.; Zhao, N.; Lin, W.; Lai, C.; Wang, Q. Largescale synthesis of uniform $\mathrm{NiCo} 2 \mathrm{O} 4$ nanoparticles with supercapacitive properties. Mater. Lett. 2015, 160, 171-174.

(57) Liu, T.; Li, Y.; Quan, G.; Dai, P.; Yu, X.; Wu, M.; Sun, Z.; Li, G. Magnetic-field-assisted preparation of one-dimensional (1-D) wirelike $\mathrm{NiO} / \mathrm{Co} 3 \mathrm{O} 4$ composite for improved specific capacitance and cycle ability. Mater. Lett. 2015, 139, 208-211.

(58) Khalaj, M.; Sedghi, A.; Miankushki, H. N.; Golkhatmi, S. Z. Synthesis of novel graphene/Co3O4/polypyrrole ternary nanocomposites as electrochemically enhanced supercapacitor electrodes. Energy 2019, 188, No. 116088.

(59) Gao, Y.; Wu, J.; Zhang, W.; Tan, Y.; Gao, J.; Tang, B.; Zhao, J. Synthesis of nickel carbonate hydroxide/zeolitic imidazolate framework-8 as a supercapacitors electrode. RSC Adv. 2014, 4, 3636636371.

(60) Deng, T.; Zhang, W.; Arcelus, O.; Kim, J. G.; Carrasco, J.; Yoo, S. J.; Zheng, W.; Wang, J.; Tian, H.; Zhang, H.; Cui, X.; Rojo, T. Atomic-level energy storage mechanism of cobalt hydroxide electrode for pseudocapacitors. Nat. Commun. 2017, 8, No. 15194.

(61) Kowalik, I. A.; Guziewicz, E.; Godlewski, M.; Arvanitis, D. Soft $\mathrm{x}$-ray absorption spectroscopy on Co doped $\mathrm{ZnO}$ : structural distortions and electronic structure. J. Phys.: Conf. Ser. 2016, 712, No. 012104. 